Article

\title{
Downdraft Assessment of Glass Curtain Wall Buildings with a Radiant Floor Heating System
}

\author{
Goosang Joe ${ }^{1}$, Dongwoo Kim ${ }^{1}$ (D), Sanghoon Park ${ }^{2}$, Sojeong Park ${ }^{3}$, Myoungsouk Yeo ${ }^{1, *}$ and \\ Kwangwoo $\mathrm{Kim}^{1}$ \\ 1 Department of Architecture and Architectural Engineering, Seoul National University, Seoul 08826, Korea; \\ lostangel@snu.ac.kr (G.J.); aeekdw@snu.ac.kr (D.K.); snukkw@snu.ac.kr (K.K.) \\ 2 LG Hausys R\&D Center, Seoul 08826, Korea; ondol@snu.ac.kr \\ 3 Department of Architecture, Jung-Gu Office, Seoul 08826, Korea; schusser@naver.com \\ * Correspondence: msyeo@snu.ac.kr; Tel: +82-2-880-7066
}

Received: 31 August 2017; Accepted: 12 October 2017; Published: 17 October 2017

\begin{abstract}
The present study aims to evaluate whether downdraft can be prevented by applying a radiant floor heating system in glass curtain wall buildings. A radiant floor heating system does not directly supply heat to cold air, but does so via heat exchange with a cold airflow. Assessing whether a downdraft is prevented is, thus, necessary. For this assessment, a radiant floor heating system was applied to perimeter zones with different window types modeled using a computational fluid dynamics (CFD) simulation. The relationship between the radiant floor heating system and the windows was examined via an assessment of the resulting downdraft by considering the radiant heat exchange effect between the window and the floor. The assessment was conducted by utilizing a CFD simulation. The simulation results show that the temperature difference between the air supplied through the radiant floor heating system and the air descending along the cold surface of the window increased when the radiant floor heating system was applied to a narrow area with a high temperature. Furthermore, the airflow velocity increased with the heat exchange. The airflow re-entered the window side, and the downdraft in the occupied area exceeded the strict value specified by the standards. Conversely, if heat were applied according to the indoor thermal output by widening the radiant heat area of the radiant floor heating system, a downdraft could occur as a result of a blocking failure prior to the influx of the cold air into the occupied area caused by low surface temperatures. Therefore, applying a radiant floor heating system is advantageous in a perimeter zone without causing airflow inducement at the window side with acceptable surface temperatures.
\end{abstract}

Keywords: downdraft; thermal comfort; radiant floor heating system; CFD

\section{Introduction}

Currently, the control of thermal comfort in indoor building environments has become increasingly important as people look for ways to improve their quality of life. The demand for efficient use of interior space is also increasing. Consequently, interest in radiant heating systems has increased and applications of this technology are becoming more widespread [1].

Radiant heating systems are advantageous in terms of thermal comfort because this system can set the air temperature to be a little low while maintaining comfort conditions through the radiation heat exchange between the occupants and the radiation surface [2]. The radiant heat transfer of a radiant heating system also covers $50 \%$ of heat exchange within a conditioned space [3], hence, it has an advantage of the temperature being uniformly supplied and maintained. Moreover, a radiant heating system is embedded in the floor or ceiling and primarily supplies radiant heat, and can, therefore, solve some problems associated with a forced convection perimeter systems, such as 
occupying a large amount of space, unpleasant discharge airflow, and noise problems caused by fans $[4,5]$.

Recently, radiant heating systems have been used in office or commercial buildings in the form of radiant floor heating systems (hereinafter RFHS) because of their thermal comfort advantages [6,7]. RFHS can also be used for direct heating in the vicinity of occupants in large, high-story spaces such as the lobbies of buildings. Because recently constructed buildings must have superior thermal performance commensurate with regulations, these windows generally have an improved $U$-value $[8,9]$. As a result, use of RFHS is increasing, reducing the heating load required for indoor heating.

However, the RFHS also has disadvantages, including its struggle to respond quickly to load changes. Although the RFHS stores heat in the thermal mass, the thermal output encounters a delay after the RFHS is heated [10,11]. The heat in the thermal mass may not be sufficient to prevent the downdraft. Thus, if the cold airflow caused by the heat transfer from the building enveloping the window side of a building is not immediately blocked, this cold airflow will invade the occupied area. A body is locally cooled, hence, the problem of local discomfort, such as in the presence of a downdraft, can occur. Until now, the method used to prevent downdraft is to use a forced convection system, such as FCU or convector. Therefore, a downdraft assessment should be conducted when an RFHS is installed in a building. The RFHS does not directly supply heat to cold air, but does so via heat exchange with a cold airflow according to the principle of natural convection. As such, assessing whether a downdraft is actually prevented is necessary.

This study aims to evaluate whether a downdraft can be prevented by an RFHS in glass curtain wall buildings, such as office buildings, restaurants, and atrium spaces etc. The RFHS does not directly supply heat to cold air, but does so via heat exchange with a cold airflow. Hence, assessing whether a downdraft is actually prevented is necessary. The downdraft assessment herein is conducted in a space where an RFHS is installed by analyzing the downdraft prevention principles according to the RFHS application. An RFHS is applied to perimeter zones with different window types modeled using computational fluid dynamics (CFD) simulation. The relationship between the RFHS and the windows is examined via an assessment of the resulting downdraft by considering the radiant heat exchange effect between the window and the floor. Based on these results, the downdraft assessment is conducted by utilizing a CFD simulation of a case, in which an RFHS is installed in a building space.

\section{Background on Downdraft Assessment}

\subsection{Definition of Downdraft}

Indoor air in close proximity to a cold window descends when it cools, owing to the window surface. If the airflow thereby generated directly touches an occupant, the occupant may feel a chill or discomfort due to the localized cooling effect resulting from a loss of heat. This phenomenon is generally defined as a downdraft. Various studies on downdrafts have been performed and the downdraft phenomenon has been defined. Representatively, downdraft was defined as "an unwanted local cooling of the human body caused by air movement" in Fanger [12], ASHRAE [13] and ISO [14]. It was also defined as "the problem caused by cold natural convective flows along glazed surfaces in winter" in Heiselberg's study [4,15]. In addition, various studies have defined downdraft [16-18], in these various studies, downdraft is described as a phenomenon generated by a cold window surface and the descending flow of natural convection. It is a phenomenon generated by the cold-window effect, cooling of the air, and descending airflow caused by a cold window surface. This study defines downdraft as a phenomenon caused by the natural convection downflow of cold airflow caused by a cold window surface. Here we assess the phenomenon in a space of curtain wall buildings where an RFHS was applied. 


\subsection{Downdraft Assessment Criteria}

There are two methods of assessing the discomfort caused by a downdraft. The first one is determining the allowable velocity of airflow in the case where the indoor temperature is within a general range. The second one is using the draft rate (DR), which evaluates the local discomfort caused by a draft. Among these, assessing the mean velocity of the airflow cannot determine the effect of a cold airflow, in other words, it has the limitation that the discomfort caused by temperature of airflow cannot be considered. Thus, in this study, the draft rate (DR), which can make a detailed assessment of airflow, was selected as the assessment parameter by considering a specific area in a room and reflecting the impact of turbulence intensity.

ASHRAE [13] divides draft rates into levels, as shown in Table 1. The draft rate separates the applicability of the standard into three steps and suggests an acceptable percentage of people who feel discomfort caused by a draft. The draft rate can be calculated as shown in Equation (1).

$$
\left.D R=\left\{\left(34-t_{a}\right) \times(v-0.05)^{0.62}\right\} \times\{(0.37 \times v \times T u)+3.14)\right\}
$$

where $D R$ is the predicted percentage of people dissatisfied due to a draft, $t_{a}$ is the local air temperature, $v$ is the local mean air speed, $T u$ is the local turbulence intensity.

Table 1. Class level of draft rate.

\begin{tabular}{ccc}
\hline Class & Draft Rate & Description \\
\hline A & $<10$ & It is desired to adhere to higher than typical comfort standards \\
B & $<20$ & Typical applications and should be used when other information is not available \\
C & $<25$ & It is desired to relax the typical comfort standards \\
\hline
\end{tabular}

This study presents the expected satisfaction level in terms of the draft rate according to the RFHS application method by deriving the indoor temperature, airflow, and draft rate distribution.

\subsection{Preliminary Study of Downdraft Assessment}

The downdraft assessment study is mostly performed by analyzing a descending flow of cold air including the velocity of the airflow and the temperature distribution, by performing an experiment or simulation.

Olesen [19] calculated the maximum velocity of an airflow for downdraft assessment and presented a range of allowable maximum airflow velocities by deriving a formula combining the height of the window and its $U$-value in a space. However, because he did not consider the temperature of the air, the cold airflow was not reflected. Heiselberg [15] evaluated the degree of downdraft occurrence by analyzing the maximum airflow velocity distribution of the descending airflow formed, depending on the surface temperature of the window via experiments under adiabatic conditions, i.e., an outdoor space and indoor space are implemented on both sides across a window. In addition, he determined the boundary layer flow in a cold airflow via flow visualization.

Manz [20] carried out a downdraft assessment in the case where there were internal heat gains, based on Heiselberg's study [15]. Manz derived the result that while warm airflow generated from internal heat gains ascends, rides the ceiling side, moves toward the window side, and descends, the velocity of the airflow increases. In this study, to reflect this result, a weighing factor of 1.5 was applied to Heiselberg's formula. Meanwhile, Hua [21] performed an experiment on air temperature, velocity of airflow, and Draft Rate (hereinafter DR) distribution, according to the distance from the wall, to analyze the occurrence of a downdraft in the case where a ventilation system was placed in the corner of the room far away from the windows. Larssons [17] analyzed the descending airflow formed because of the thermal performance of the window and width of the windowsill in the experimental room where the window was located on the upper side of a wall. Schellen [22] performed the 
assessment of downdraft through experiments and CFD simulation to analyze the velocity of airflow and DR according to the height and surface temperature of the windows. Jurelionis [23] analyzed the occurrence of downdraft by presenting the Predicted Percentage of Dissatisfied (hereinafter PPD) distribution in the room through the CFD simulation. In this study, the maximum velocity of airflow according to the thermal performance of windows was evaluated by comparing the formulas of Heiselberg [15] and Manz [20]. Additionally, the limiting height of the exterior envelope, so as not to result in discomfort caused by the downdraft was presented. Similarly, Myhren [24] analyzed the airflow velocity distribution in the room according to various heating methods to evaluate the reduction of downdraft through the heating of cooled air. In Mustakallio's study [25], thermal conditions of an office room with a CBRP (chilled beam having an integrated radiant panel) in heating mode were analyzed. The results of this study indicate that radiant panel heating is also an applicable solution in cold climates. Favorable thermal conditions can be ensured when the temperature of the window surface is at least $14-15^{\circ} \mathrm{C}$. At the same time, the vertical temperature stratification is acceptable.

The experimental studies evaluating downdraft did not reflect the external environmental conditions affecting the downdraft well, because most of the experiments were conducted under insulated space conditions. The CFD studies did not consider the temperature deviation of the window surface caused by the descending airflow and the effect of the temperature rise of the window caused by the radiation heat exchange, thereby judging the surface temperature of the window to be fixed.

Therefore, in this study, the downdraft was assessed by considering the external environmental conditions and the thermal environment changes in the space. The effects of heating the windows with radiant heat of the RFHS and the natural convection effect were considered to improve the existing research results.

\section{Assessment Parameters}

\subsection{Mechanism of Downdraft Prevention}

A downdraft occurs when air is cooled on the inside of a window as the heat transferred to the cold outside surroundings is enhanced, and the air in close proximity to the inside of the window is cooled as it loses heat to the cold window surface. According to Peng's study [26], the heat transfer phenomenon that occurs when heat is supplied from the floor below a cold window is different from the case when heat is supplied from a general vertical surface because of the heat exchange between the cold window and the floor. Moreover, RFHS supply heat to the cold air indirectly, in others words, it slowly supplied heat through the principle of natural convection. Thus, to assess whether an RFHS can actually prevent a downdraft, the interior heat transfer phenomenon caused by the heat exchange between an RFHS and cold windows must be analyzed and an RFHS application method that can prevent downdrafts must be developed.

To prevent downdrafts when using an RFHS, the influx of the airflow should be blocked by raising the surface temperature of the RFHS and supplying heat to the cold airflow formed near the windows [27]. In other words, when cold air forms near a cold window and moves along the floor surface, the RFHS should raise the temperature of the air over a large radiating surface to block the cold airflow influx into the occupied area by forming an ascending flow caused by a warm airflow of RFHS. However, because the radiant heat resulting from the higher surface temperature of the RFHS relative to indoor thermal equilibrium leads to indoor overheating and occupant discomfort, the RFHS must be applied according to the required heating load in the space. The radiation area must be reduced to increase the surface temperature of the RFHS according to the heating load required in the room. That is, for the same thermal output, the narrower the radiation area, the higher the surface temperature, the wider the radiation area, and the lower the surface temperature. Because downdraft is generated by the effects of the indoor air temperature and airflow velocity, the indoor air temperature and the airflow velocity formed by the radiation area and surface temperature of 
the RFHS are important. Thus, it is necessary to analyze the effects of the radiation area and surface temperature of the RFHS on the temperature of the indoor air and the airflow velocity.

If the cold airflow generated by the cold surface of a window in a space where an RFHS has been applied descends and flows into the occupied zone, heat is transferred to the cold airflow. The temperature rises and the warm airflow generated from the RFHS forms an ascending flow, blocking the indoor influx of cold airflow. Because an RFHS is applied to a narrow area with a high surface temperature, the indoor influx of cold air is blocked and a high air temperature in the vicinity of the inner floor surface results as shown in Figure 1. As the temperature difference between the cold air that flows along the floor surface and the warm air generated from the surface of the RFHS becomes larger, the airflow velocity at the floor surface increases. On the other hand, if heat is supplied according to the required heat demand in the space by widening the radiant heating area of the RFHS, the air temperature near the floor surface is relatively low compared to the case shown in Figure 2. However, the airflow velocity at the floor surface can be reduced because the temperature difference between the warm floor surface and the cold window surface is reduced.

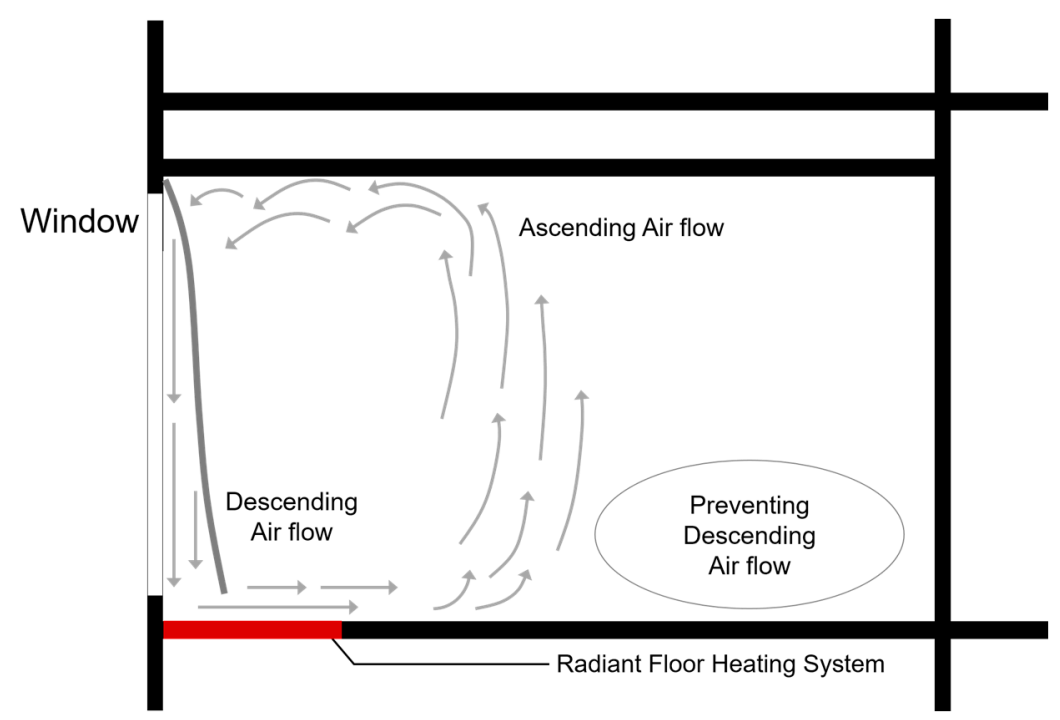

Figure 1. Airflow by application of radiant floor heating systems (RFHS) (narrow area/high surface temperature).

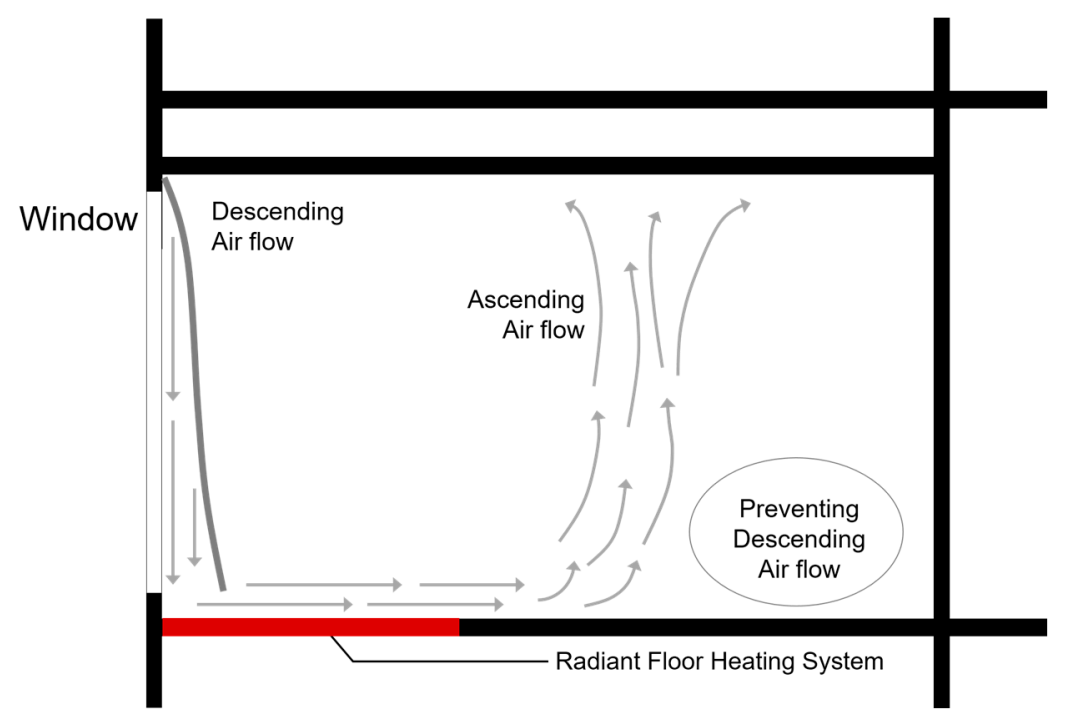

Figure 2. Airflow by application of RFHS (wide area/relatively low surface temperature). 
The downdraft is intensified with decreasing air temperature and increasing air velocity. Therefore, to prevent downdraft in a space where an RFHS is applied, when the RFHS is applied near windows, it should raise the temperature of the cold airflow sufficiently by establishing a suitable surface temperature and should not cause an increase in airflow velocity due to a temperature difference while supplying heat.

\subsection{Method for Downdraft Assessment}

The occurrence of a downdraft is possible to predict using the height and width of the draft rate, as shown in Figure 3, in which the height of the downdraft is the length of the $y$-axis and the width of the downdraft is the length of the $x$-axis beyond an allowable standard. According to the analysis of the flow using the draft rate during RFHS application, the airflow velocity appears high due to the descending airflow, and the air temperature is distributed at low values. For this reason, the numerical value of the draft rate near windows appears high, but gradually becomes lower because the RFHS reduces the cold airflow as air enters the room.

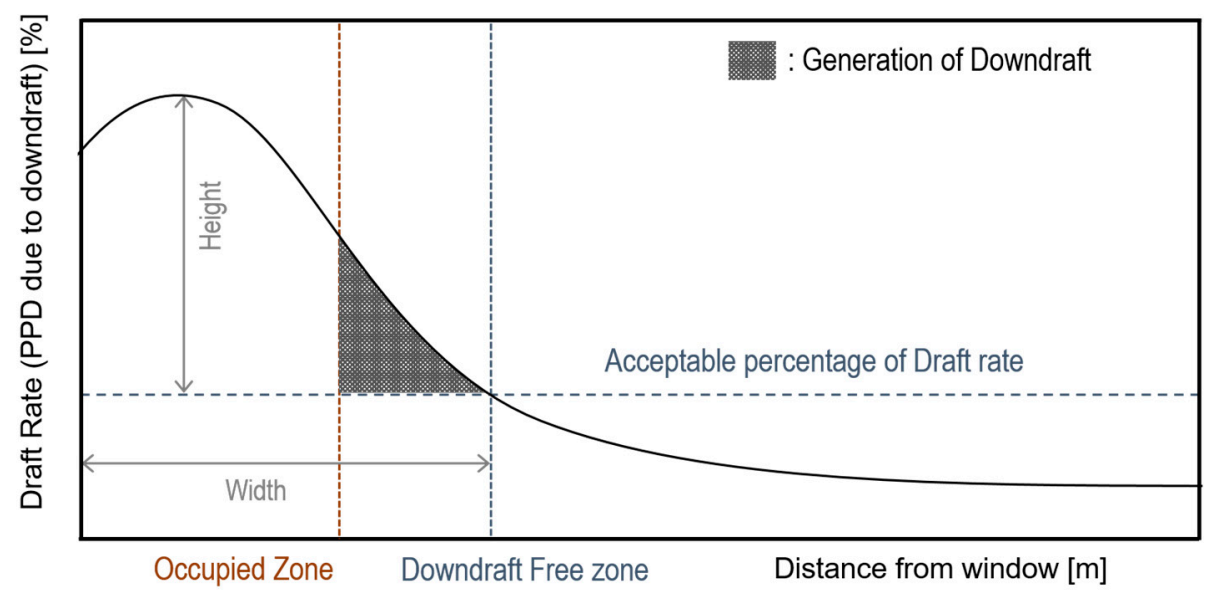

Figure 3. Distribution of draft rate by application of RFHS.

Because a downdraft is a phenomenon whereby an occupant feels discomfort depending on the qualitative senses of the human body, an area occupied for long periods of time was selected as the space for downdraft assessment. Although the magnitude of the draft rate in the vicinity of the windows appears higher than the allowable reference value, it may be determined that a downdraft does not occur if the draft rate within the occupied area appears lower than the allowable reference value.

\subsection{Parameters for Downdraft Assessment}

To reduce cold airflow and assess the downdraft in a space where an RFHS is applied, the radiant heat condition such as thermal output and radiation area of the RFHS should be considered to transfer heat indirectly to the cold airflow and form an ascending airflow, additionally, the indoor environment, which affects the downdraft, should also be considered. Parameters that affect temperature and velocity of the airflow near the floor include the surface temperature and radiation heat area of the RFHS in accordance with the mechanism of preventing downdraft (3.1). Thus, these quantities were selected as assessment parameters that affect downdraft.

When using an RFHS, to reflect the indoor environment conditions that should be considered in downdraft prevention, parameters affecting downdraft in indoor spaces were derived by considering existing research. Eckert's study [28] involved a theoretical analysis of the turbulent natural convection flow above the cold surface of windows. Based on Eckert's study [28], Heiselberg [15] derived the maximum velocity of the airflow in Equations (2)-(4) by measuring the minimum air temperature near the floor surface when the cold air formed by the cold surface of the window moves along the 
floor surface owing to the descending flow caused by natural convection. According to the obtained results, as the vertical height of the cold window surface increases and the temperature difference between the surface of the window and the occupied area increases, the maximum velocity of the airflow at ankle height increases. However, the area of interest in downdraft assessment is not the area close to the cold external surface, but rather the area in which people actually reside. Therefore, Heiselberg [15] evaluated the maximum velocity of the airflow and the minimum temperature close to the floor surface as cold airflow descends and flows along the floor to assess the risk of an occupant feeling a downdraft.

According to experimental results, the maximum velocity and minimum temperature of the airflow were measured within $0.4 \mathrm{~m}$ of the cold surface. Then, the velocity of the airflow was reduced up to a distance of $2 \mathrm{~m}$ from the window, and the maximum velocity of the airflow was reduced by more than $25 \%$ at a point more than $2 \mathrm{~m}$ away and then remained constant.

$$
\begin{gathered}
u_{\max }=0.055 \sqrt{(h \Delta t)} x<0.4 \\
u_{\max }=0.095 \frac{\sqrt{(h \Delta t)}}{x+1.32} 0.4 \leq x \leq 2.0 \\
u_{\max }=0.028 \sqrt{(h \Delta t)} 2.0>x
\end{gathered}
$$

where $u_{\max }$ is the maximum velocity at the bottom of the cold surface, $h$ is the height in meters of the vertical surface, $\Delta t$ is the temperature difference between the cooled surfaces in reference to the occupied zone, $x$ is the distance from the window (cold surface).

According to these findings, a downdraft is mainly generated near the floor surface as the airflow formed by the cold surface of a window moves along the floor surface. The velocity of the airflow entering the occupied space along the floor surface is influenced by the descending velocity of the cold airflow formed near the window.

The maximum velocity of the airflow in proximity to the window increases as the surface temperature of the window decreases and as the vertical height of the window increases. Therefore, the thermal performance of the window (i.e., the $U$-value of the window), which determines the surface temperature of the window and is related to its heat insulation properties, and the vertical height of the window, which affects the descending velocity of the cold airflow formed near the window, were selected as indoor downdraft assessment parameters.

\section{CFD Simulation}

\subsection{Description}

The target space representing a prototype of a general office building was established to assess the downdraft in a space, where an RFHS was applied. We tried to evaluate herein in severe indoor and outdoor environment conditions with a high possibility of downdraft. In other words, we assumed that the downdraft can be prevented in better indoor and outdoor environment conditions if it could be prevented when RFHS was applied in an environment with a high possibility of downdraft occurrence. In addition, reflecting the current trend of improving the thermal performance of windows, the downdraft assessment was conducted for cases where the thermal performance of the windows was improved because the indoor thermal environment may be different when the thermal performance of the windows improves.

In the target space, glass was used for the entire outer surface. The temperature of the ambient air parameters was set to ambient conditions during the winter maximum load calculation. The $U$-value of the window was set to that of a general dual-pane glass (mostly equipped in high-rise buildings over 20 floors in Seoul, South Korea) window and a low-E dual pane glass (mostly commonly equipped in windows in new or renovated buildings in the last 3 years in Seoul, South Korea). We did not consider 
the impact of infiltration herein to focus on the downdraft assessment caused by the heat exchange between the cold window and the RFHS. Solar radiation and internal heat gains were also neglected. Table 2 shows the target space conditions.

Table 2. Conditions of target space.

\begin{tabular}{|c|c|c|}
\hline \multicolumn{2}{|c|}{ Classification } & Description \\
\hline \multicolumn{2}{|c|}{ Target space area } & $6(\mathrm{~m}) \times 7(\mathrm{~m}) \times 3(\mathrm{~m})(\mathrm{w} \times \mathrm{d} \times \mathrm{h})$ \\
\hline \multicolumn{2}{|c|}{ Temperature conditions } & Outdoor: $-11.3^{\circ} \mathrm{C} /$ Indoor: $20^{\circ} \mathrm{C}$ \\
\hline \multirow{2}{*}{ Window conditions } & Type & general dual-pane glass/Low-E dual-pane glass \\
\hline & $U$-value & $2.75 \mathrm{~W} / \mathrm{m}^{2} \cdot \mathrm{K} / 1.75 \mathrm{~W} / \mathrm{m}^{2} \cdot \mathrm{K}$ \\
\hline \multirow{2}{*}{$\begin{array}{l}\text { Radiant floor heating system } \\
\text { conditions }\end{array}$} & Heating area & $1.0 \mathrm{~m}, 3.0 \mathrm{~m}, 7.0 \mathrm{~m}$ distance from Window \\
\hline & Surface Temp. & $\begin{array}{l}\text { According to a heating area (Perimeter zone: } \\
\text { Maximum } 41^{\circ} \mathrm{C} \text {; Interior zone: Maximum } 29^{\circ} \mathrm{C} \text { ) }\end{array}$ \\
\hline \multicolumn{2}{|c|}{ Wall condition } & Adiabatic \\
\hline
\end{tabular}

\subsection{Boundary Conditions}

To evaluate the temperature and velocity of the indoor airflow, whose parameters impact the downdraft, and the distribution of the draft rate, which is an indicator of a downdraft, a simulation analysis of the indoor environment was performed using the commercial CFD software STAR-CCM+12.02. STAR-CCM+ accurately predicts heat transfer in fluids and solids using specialized convection, conduction and radiation models. The automated meshing tools and parts-based simulation option allow validating thermal designs faster [29]. The physical condition of the simulation is described in Table 3. The simulation is interpreted by applying the K- $\varepsilon$ turbulence model under a steady-state condition. To accurately analyze the ascending effect of the indoor airflow caused by the RFHS, the simulation was performed by applying the Boussinesq model. The details about the numerical models of the CFD simulation are shown in Figure 4.

The mesh was composed of polyhedral elements, which were a non-regular lattice that can cope with complex shapes. The number of surface meshes analysis was 23,914 , and the volume mesh analysis was 72,432. The layer and the immediate space of the window, the edges of the room, and the area, where the window and the room were connected, were formed by a finer mesh. Figure 5 presents the mesh constructed for the simulation. The mesh geometry was appropriately constructed without collapsing or tangling. Moreover, no errors occurred, including the fine-meshed parts.

Table 3. Model of simulation.

\begin{tabular}{ccc}
\hline & Physics Model & Description \\
\hline \multirow{4}{*}{ Physics } & Time & Steady state \\
& Turbulence model & K- $\varepsilon$ Turbulence \\
& Radiation & Surface-to-surface Radiation \\
& Equation of state & Ideal Gas (Including Boussinesq Model) \\
\hline
\end{tabular}



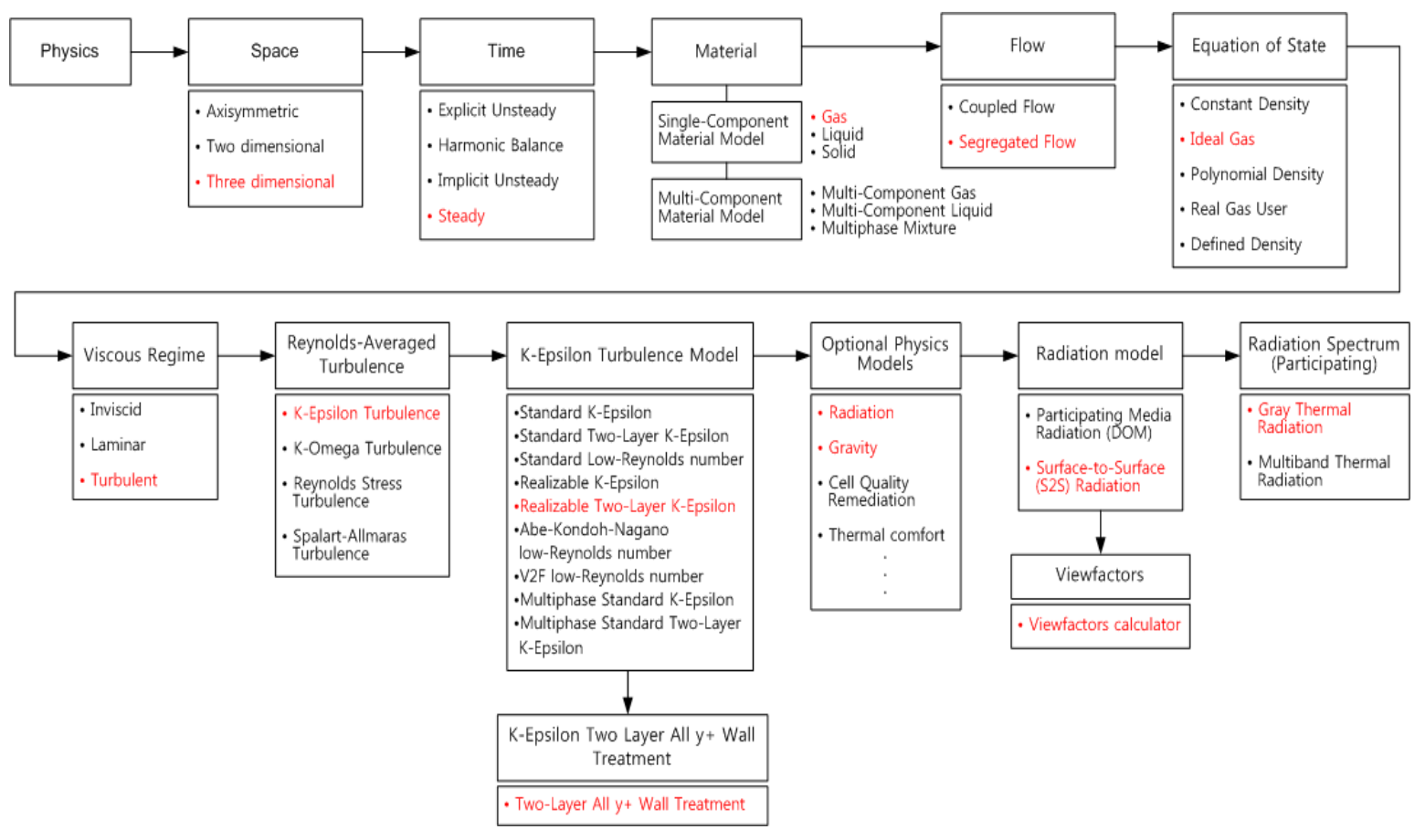

Figure 4. The numerical models of the computational fluid dynamics (CFD) simulation.

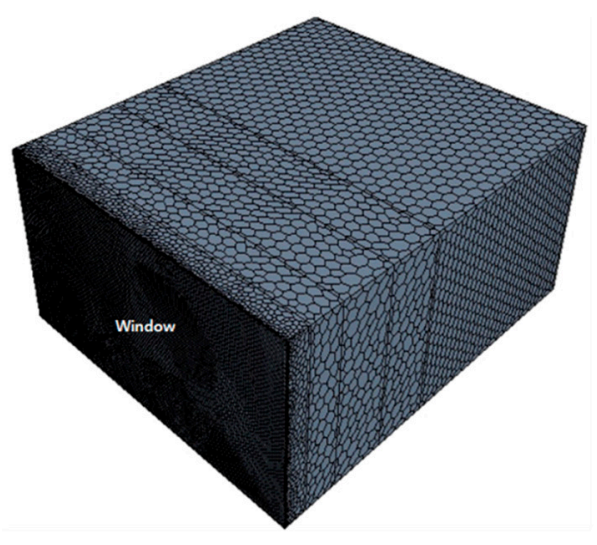

(a) Aeroview of mesh

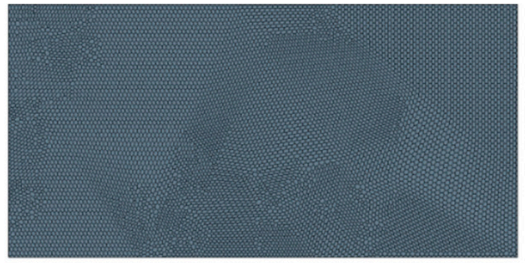

(b) Front view of window

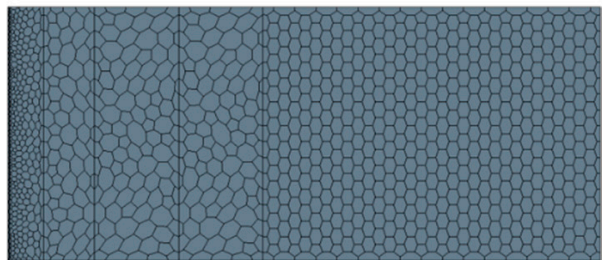

(c) Side view of wall

Figure 5. Generation of mesh model.

The analysis results of the perimeter zone standard for perimeter zone application of the RFHS showed that the maximum $1.0 \mathrm{~m}$ distance from the window was presented as the perimeter zone in ISO 11588 [30] and a $3.0 \mathrm{~m}$ distance from the window (or 1/3 degree of actual depth during the perimeter zone system design) was used. Thus, the radiation area of the floor surface was set for the case in which the RFHS was applied to the perimeter zone. It was assumed that the RFHS was heated up to the load to be removed and that all heating loads generated in the room would be removed through the RFHS. In other words, the thermal output of the RFHS was equal to the heat loss by conduction through the building envelope (i.e., in this study, the window). This is shown in Equation (5). The thermal output can be expressed as the relationship of heat flow intensity and the surface area of the radiant heating 
panel as shown in Equations (6) and (7). The surface temperature of the RFHS was determined by its thermal output, which can be calculated using Equation (8) as represented in EN [31].

$$
\begin{gathered}
Q_{R}+Q_{W}=0 \\
\left(q_{r} \times A_{r}\right)+\left(q_{w} \times A_{r}\right)=0 \\
\left(q_{r} \times W_{r} \times L_{r}\right)+\left\{K_{w} \times A_{w} \times\left(t_{\text {room }}-t_{\text {out }}\right)\right\}=0
\end{gathered}
$$

where $Q_{R}$ is the thermal output of surface heating, $Q_{W}$ is the heat loss through the window, $q_{r}$ is the heat flow density (heat flux) at the surface of the RFHS, $q_{w}$ is the heat loss through window per unit area, $A_{r}$ is the heating surface area of the RFHS, $A_{w}$ is the surface area of the window, $W_{r}$ is the width of the RFHS, $L_{r}$ is the length of the RFHS, $K_{w}$ is the heat transmission coefficient ( $U$-value) of the window, $t_{\text {room }}$ is the nominal indoor temperature, $t_{\text {out }}$ is the outside temperature.

$$
q_{p}=8.92\left(t_{\text {surf }}-t_{\text {room }}\right)^{1.1}
$$

where $q_{p}$ is the heat flow density of the RFHS, $t_{\text {surf }}$ is the average surface temperature of the RFHS, $t_{\text {room }}$ is the room indoor temperature.

\subsection{Simulation Cases}

Depending on the radiation area and surface temperature, which were the RFHS parameters selected in advance, and the $U$-value and vertical height of the window, which are the indoor environment assessment parameters, the velocity and temperature distribution of the indoor airflow and the height and width of the draft rate were analyzed.

Assessments of the case where an RFHS was applied within the perimeter zone and the case where a RFHS was applied to the entire floor were performed. The surface temperature was established as $41{ }^{\circ} \mathrm{C}$ in the case where the radiation region was $1.0 \mathrm{~m}$ in the simulation, which exceeded the $35^{\circ} \mathrm{C}$ value, specified as a standard by ASHRAE [13] and ISO [14]. The perimeter zone limited the surface temperature of the floor. On the other hand, according to Wang's study [32] on the limitation of the acceptable floor surface temperature, within the air temperature range of $17-27^{\circ} \mathrm{C}$, the acceptable floor surface temperature can be increased beyond $41^{\circ} \mathrm{C}$. In addition, according to the CENELEC [33], in the case of the perimeter zone, because the effects on the human body are small in spaces where people directly reside, floor surface temperature limits were established according to burn threshold hours. Therefore, the downdraft assessment was performed by applying the tempered limit temperature criteria. However, this tempered limit temperature criteria and the thermal output of some simulation cases cannot be applied when an actual RFHS is installed in buildings. Hence, they were used only as a reference for the downdraft assessment by the radiation area and the surface temperature of the RFHS.

As the air temperature distribution and maximum velocity of the airflow in the target space can be different according to the $U$-value of a window, the thermal performance of the window, which is an indoor downdraft assessment parameter, and the vertical height of the window, which affects the descending velocity of the cold airflow, were analyzed. The velocity of the indoor airflow, its temperature distribution, and the height and width of the draft rate according to the $U$-value and vertical height of window were assessed. Based on these analyses, a simulation case for assessment was selected and is shown in Table 4. 
Table 4. Configuration of the simulation cases.

\begin{tabular}{|c|c|c|c|c|c|c|}
\hline \multicolumn{7}{|c|}{ Parameters Of Radiant Floor Heating System } \\
\hline \multirow{3}{*}{ Case } & \multicolumn{4}{|c|}{ Radiant Floor Heating System } & \multicolumn{2}{|c|}{ Window } \\
\hline & \multicolumn{2}{|c|}{ Thermal Output } & \multirow{2}{*}{$\begin{array}{l}\text { Heating } \\
\text { Area }\left(\mathrm{m}^{2}\right)\end{array}$} & \multirow{2}{*}{$\begin{array}{c}\text { Surface } \\
\text { Temp. }\left({ }^{\circ} \mathrm{C}\right)\end{array}$} & \multirow{2}{*}{$\begin{array}{l}U \text {-Value } \\
\left(\mathrm{W} / \mathrm{m}^{2} \cdot \mathrm{K}\right)\end{array}$} & \multirow{2}{*}{ Height (m) } \\
\hline & $\left(\mathrm{W} / \mathrm{m}^{2}\right)$ & $(W)$ & & & & \\
\hline (1) & 258.22 & \multirow{4}{*}{1549.35} & $6(1)$ & 41.0 & \multirow{4}{*}{2.75} & \multirow{4}{*}{3.0} \\
\hline$(2)$ & 129.11 & & $12(2)$ & 31.3 & & \\
\hline (3) & 86.07 & & $18(3)$ & 27.8 & & \\
\hline (4) & 36.88 & & $42(7)$ & 23.6 & & \\
\hline \multicolumn{7}{|c|}{ Parameters of Radiant Floor Heating System and Window } \\
\hline \multirow{3}{*}{ Case } & \multicolumn{4}{|c|}{ Radiant Floor Heating System } & \multicolumn{2}{|c|}{ Window } \\
\hline & \multicolumn{2}{|c|}{ Thermal Output } & Heating & Surface & $U$-Value & Heioht (m) \\
\hline & $\left(\mathrm{W} / \mathrm{m}^{2}\right)$ & $(W)$ & Area $\left(\mathrm{m}^{2}\right)$ & Temp. $\left({ }^{\circ} \mathrm{C}\right)$ & $\left(\mathrm{W} / \mathrm{m}^{2} \cdot \mathrm{K}\right)$ & \\
\hline (5) & 164.32 & \multirow{4}{*}{985.95} & $6(1)$ & 34.1 & \multirow{4}{*}{1.75} & \multirow{4}{*}{3.0} \\
\hline (6) & 82.16 & & $12(2)$ & 27.5 & & \\
\hline (7) & 54.77 & & $18(3)$ & 25.2 & & \\
\hline (8) & 23.47 & & $42(7)$ & 22.4 & & \\
\hline (9) & 258.22 & \multirow{2}{*}{3098.70} & $12(2)$ & 41.0 & \multirow{2}{*}{2.75} & \multirow{4}{*}{6.0} \\
\hline$(10)$ & 73.77 & & $42(7)$ & 26.7 & & \\
\hline (11) & 164.32 & \multirow{2}{*}{1971.90} & $12(2)$ & 34.1 & \multirow{2}{*}{1.75} & \\
\hline (12) & 46.95 & & $42(7)$ & 24.5 & & \\
\hline
\end{tabular}

() is distance from window (unit is $\mathrm{m}$ ).

\subsection{Validation}

The simulation model was validated prior to the downdraft assessment according to the RFHS application. This was also done for Heiselberg's experiment [15], which evaluated the degree of downdraft by analyzing the maximum velocity of the descending airflow distribution formed according to the surface temperature of the window. A comparative analysis between the maximum velocity of the airflow distribution derived from Heiselberg's experiment and that measured at the same position in the simulation target space was also performed.

Heiselberg's experiment has been quoted to validate the results in studies, such as those of Larssons [17], Manz [20], Schellen [22], and Jurelionis [23], among others, and is the experimental study widely used in recent downdraft assessments. Therefore, in the present study, a validation was performed based on the experimental results of Heiselberg's experiment, judging that Heiselberg's experiment is reliable. However, an error was found in the experiment, and a limitation was not reflected in the validation of this study because the experimental error was not presented in detail. Therefore, the error of the experiment and the study simulation may be larger than the value presented in this study. A further validation is necessary through experiments suitable for this study in the future. Table 5 presents the simulation implementation conditions in Heiselberg's experiment and in this study.

To implement the simulation under the same conditions as in Heiselberg's experiment, a space of the same size was simulated. In Heiselberg's experiment, a panel was maintained at a constant temperature to represent a window, but in this study, a window was implemented as a solid surface with a thickness. The external space was simulated using a convection condition, while the thermal 
environment outside was modeled to represent the change in the window surface temperature through radiative and convective heat transfer to the window during use of an RFHS.

Table 5. Simulation implementation condition in the Heiselberg's experiment and this study.

\begin{tabular}{ccc}
\hline Classification & Heiselberg's Experiment & This Study's Simulation \\
\hline Indoor area & $6(\mathrm{~m}) \times 7(\mathrm{~m}) \times 3(\mathrm{~m})(\mathrm{w} \times \mathrm{d} \times \mathrm{h})$ & $6(\mathrm{~m}) \times 7(\mathrm{~m}) \times 3(\mathrm{~m})(\mathrm{w} \times \mathrm{d} \times \mathrm{h})$ \\
Window surface temp. & $10 \sim 16^{\circ} \mathrm{C}$ & $10 \sim 12{ }^{\circ} \mathrm{C}\left(\right.$ Outdoor : $-11.3^{\circ} \mathrm{C} / \mathrm{U}$-value: $\left.2.75 \mathrm{~W} / \mathrm{m}^{2} \cdot \mathrm{K}\right)$ \\
Room temp. & $18 \sim 20^{\circ} \mathrm{C}$ & $18 \sim 20^{\circ} \mathrm{C}$ \\
\hline
\end{tabular}

For the $U$-value of the window, the conditions under which a window would lose the same amount of heat as that lost by a radiant panel releasing cold in Heiselberg's experiment were applied. In addition, in the experiment, heat was transferred through the remaining walls and ceiling to provide the amount of heat loss by the window. In the simulation, the walls and ceiling applied a temperature condition to ensure the same amount of heat transfer as in the experimental condition. The validation results of the simulation are shown in Figures 6 and 7.

The maximum velocity distribution of the airflow in the simulation showed a tendency similar to the maximum velocity of the airflow derived from Heiselberg's experiment as shown in Figure 6 . The relative error ranged from a minimum of $0.01 \%$ to a maximum of $13.32 \%$ with an average error of $6.36 \%$ and a standard deviation of $3.42 \%$. As a result of the draft rate comparison as shown in Figure 7 , the minimum error was $0.01 \%$, and the maximum error was $13.33 \%$. The average error was $6.05 \%$, and the standard deviation was $3.32 \%$. The relative error of the air velocity and the draft rate increased as the distance from the window increased. This error was caused by the experiment being evaluated as a fixed value from $2 \mathrm{~m}$ from the window. The error was high near the window and judged as an error caused by the difference of the window temperature distribution in the experiment of Heiselberg and the simulation in the present study.

Therefore, the validation results implied that the simulation model had an average reliability of $6.20 \%$ and a standard deviation of $3.35 \%$ when a total error of the air velocity and the draft rate are included.

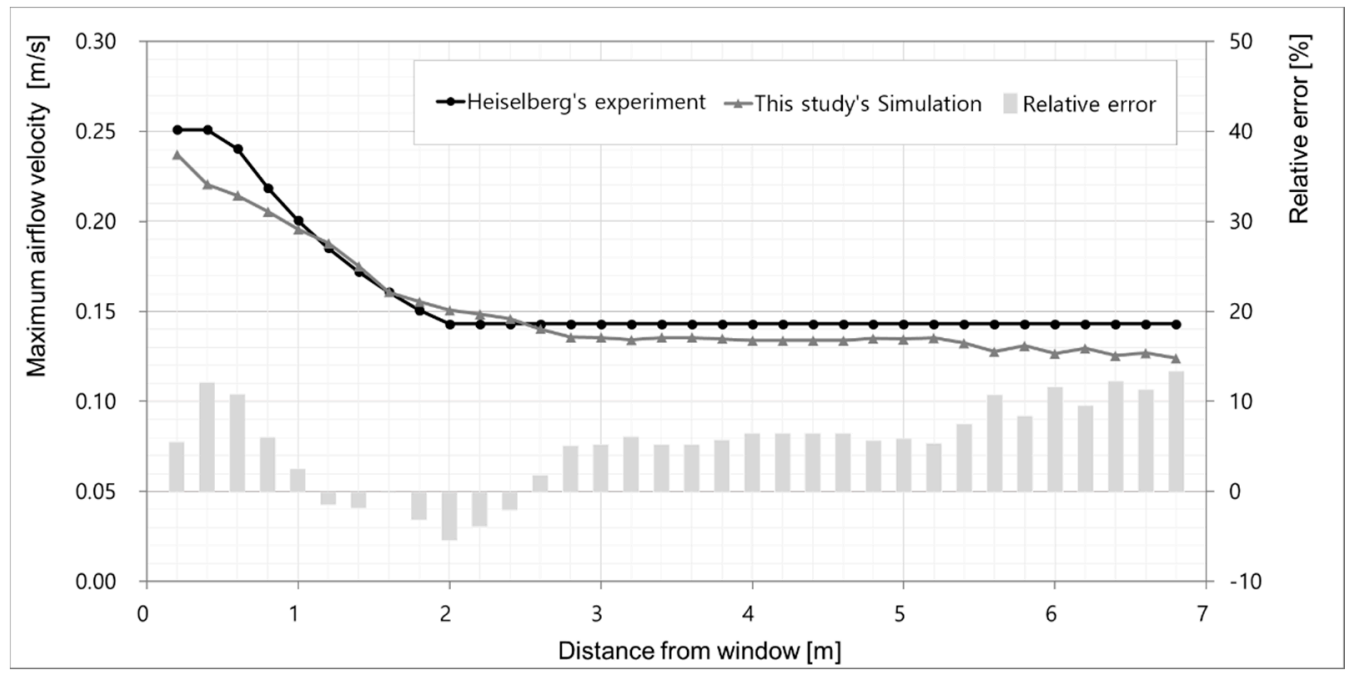

Figure 6. Result of maximum airflow velocity comparison. 


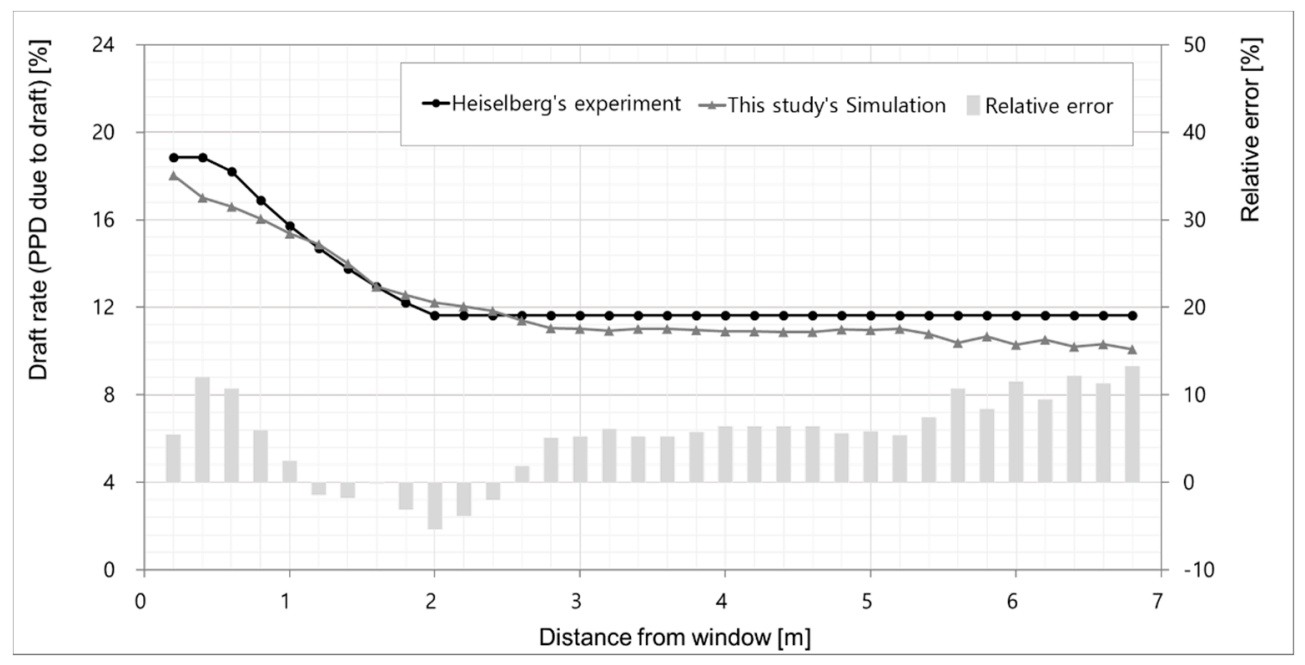

Figure 7. Result of draft rate comparison.

\section{Results and Discussion}

\subsection{Effect of Floor Temperature and RFHS Radiant Area}

According to the model condition of the assessment target space set in advance, the assessment considered cases where the RFHS was partially applied to the perimeter zone or applied to the entire floor. Based on this, the simulation results according to the RFHS parameters were derived.

\subsubsection{Velocity Profiles}

The air distribution formed according to the RFHS radiation area and surface temperature condition is shown in Figure 8. According to the results, where the narrowest radiation area and the highest surface temperature were applied, the velocity of the airflow in the vicinity of the floor surface was distributed at high values as the temperature difference between the descending cold air from the cold window and warm air from the floor increased. Additionally, as the cold air moved along the floor surface (also side wall) toward the inside of the room and the temperature rose more quickly, the warm ascending airflow from the floor appeared reasonably close to the window. This airflow was attracted to the area where relatively low-density air was distributed as cold air descended. When comparing this with Myhren's results [25], which reflect the infiltration condition, the velocity of the airflow in the vicinity of the window was distributed at high values owing to the high temperature and related attraction effect of the RFHS, even without infiltration, and the entry of this airflow into the inside of the room was shown. Moreover, as the radiant area of the RFHS was applied more widely and the surface temperature was applied less, the velocity of the airflow from the floor surface was reduced. As a result, the phenomenon of heat influx into the window caused by the ascending airflow from the floor's surface near the window and opposite side wall was reduced.

\subsubsection{Temperature Distribution}

The temperature distribution of the indoor vertical cross section is shown in Figure 9. In case (01), the air temperature close to the set temperature $\left(20^{\circ} \mathrm{C}\right)$ in thermal equilibrium was generally distributed in the occupied area by blocking the cold air formed near the window, but in case (04), relatively low air temperatures extended deep into the room. However, because a temperature of $18.5^{\circ} \mathrm{C}$ to $21^{\circ} \mathrm{C}$ was distributed throughout the room (Including all volume of the room) and the vertical temperature difference showed a maximum of $2.5^{\circ} \mathrm{C}$, it was determined that occupant discomfort would not occur compared with the standards of indoor temperature and vertical temperature differences. Also, 
floor temperature is maintained within comfort range (about $23^{\circ} \mathrm{C}$ to $32{ }^{\circ} \mathrm{C}$ ). However, the portion with a low indoor temperature had a high downdraft occurrence probability because of cold air.

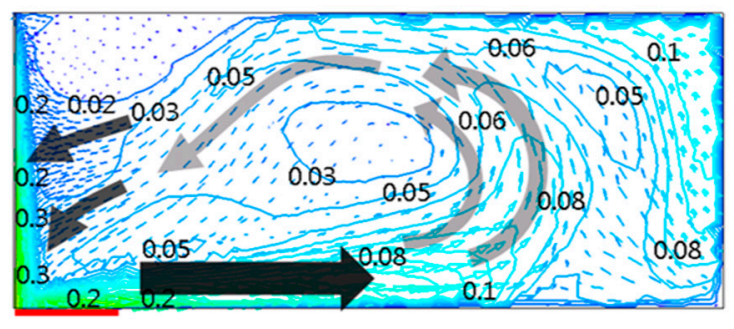

Case (1)

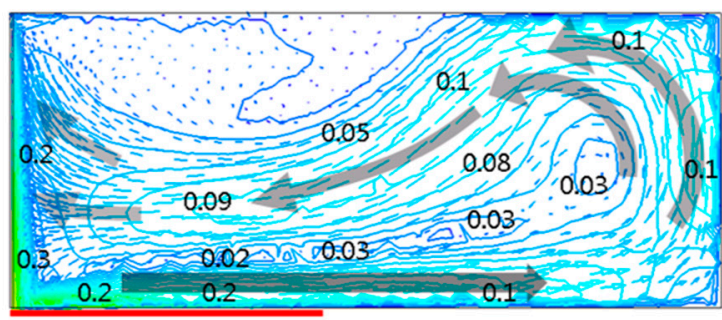

Case (3)

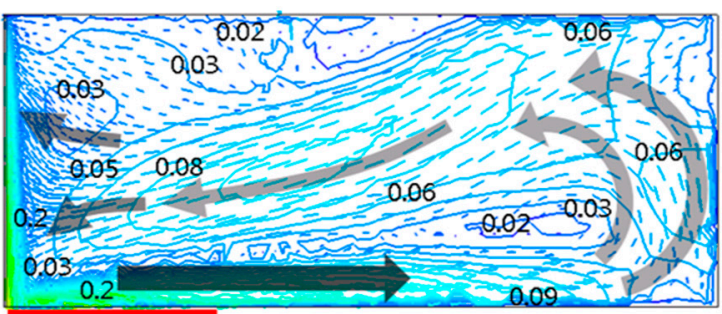

Case (2)

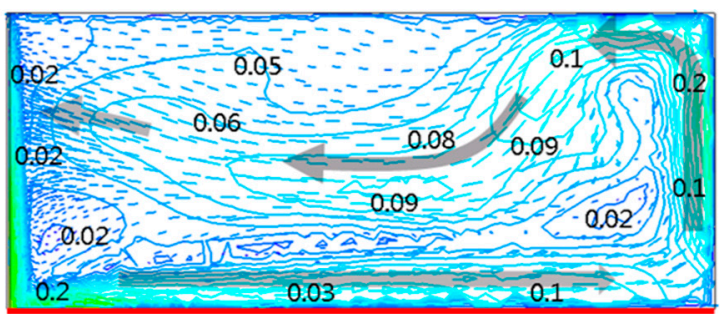

Case (4)

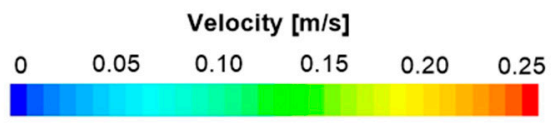

Figure 8. Velocity profiles.

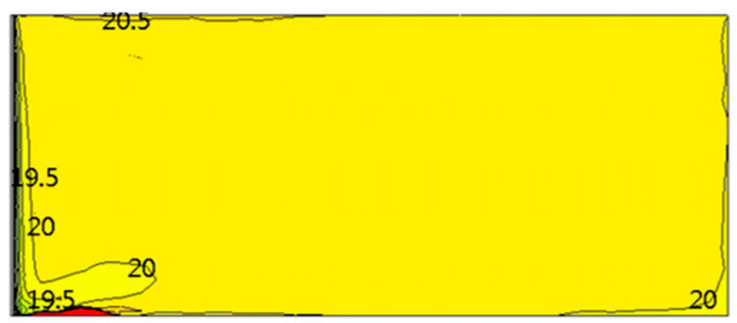

Case (1)

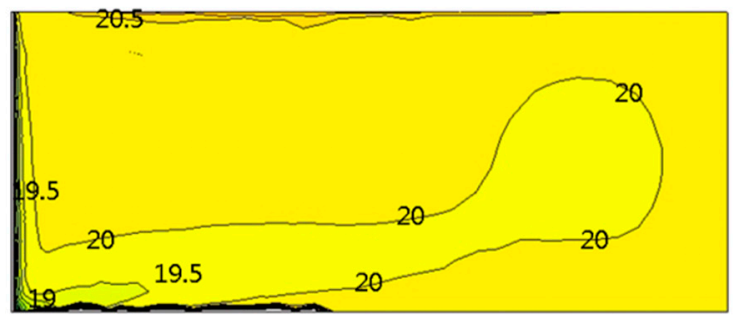

Case (3)

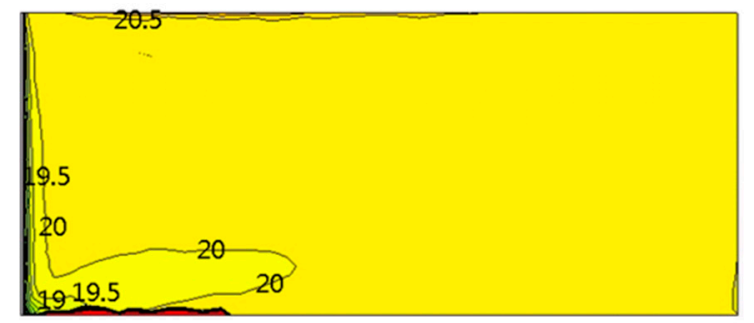

Case (2)

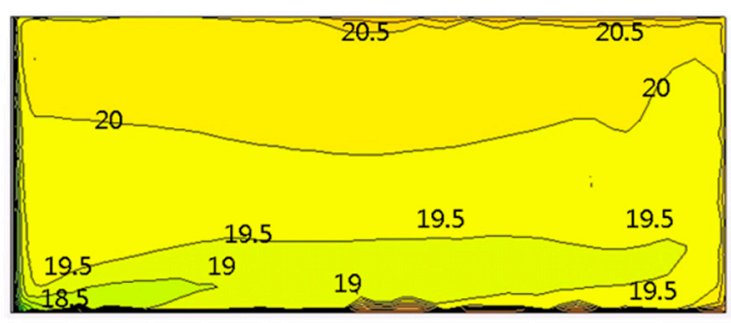

Case (4)

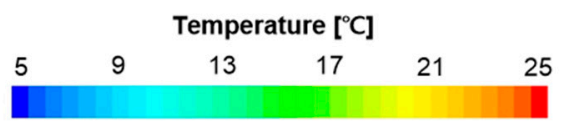

Figure 9. Distribution of temperature.

\subsubsection{Predicted Percentage of People Dissatisfied Due to Downdraft}

The numerical value of the maximum draft rate over the floor surface for each case was derived as shown in Figure 10 (here, reference point is DR 10\%). Similar to Schellen's results [23], a high draft 
rate was observed at the bottom of the window, but tended to decrease with lower airflow velocity and higher indoor temperature. On the other hand, case (04), where the RFHS was applied to the entire floor surface, showed the highest draft rate value because of a failure to block the influx of cold air into the occupied area with a low window surface temperature. In the case where a radiative surface was applied in the narrowest way, the airflow velocity was distributed at significantly higher values than in the other case. This was because the temperature difference between the surface temperature of the RFHS and the air from the window was high, but the draft rate was relatively low because of the high temperature of the air near the floor established by supplying heat at a high temperature.

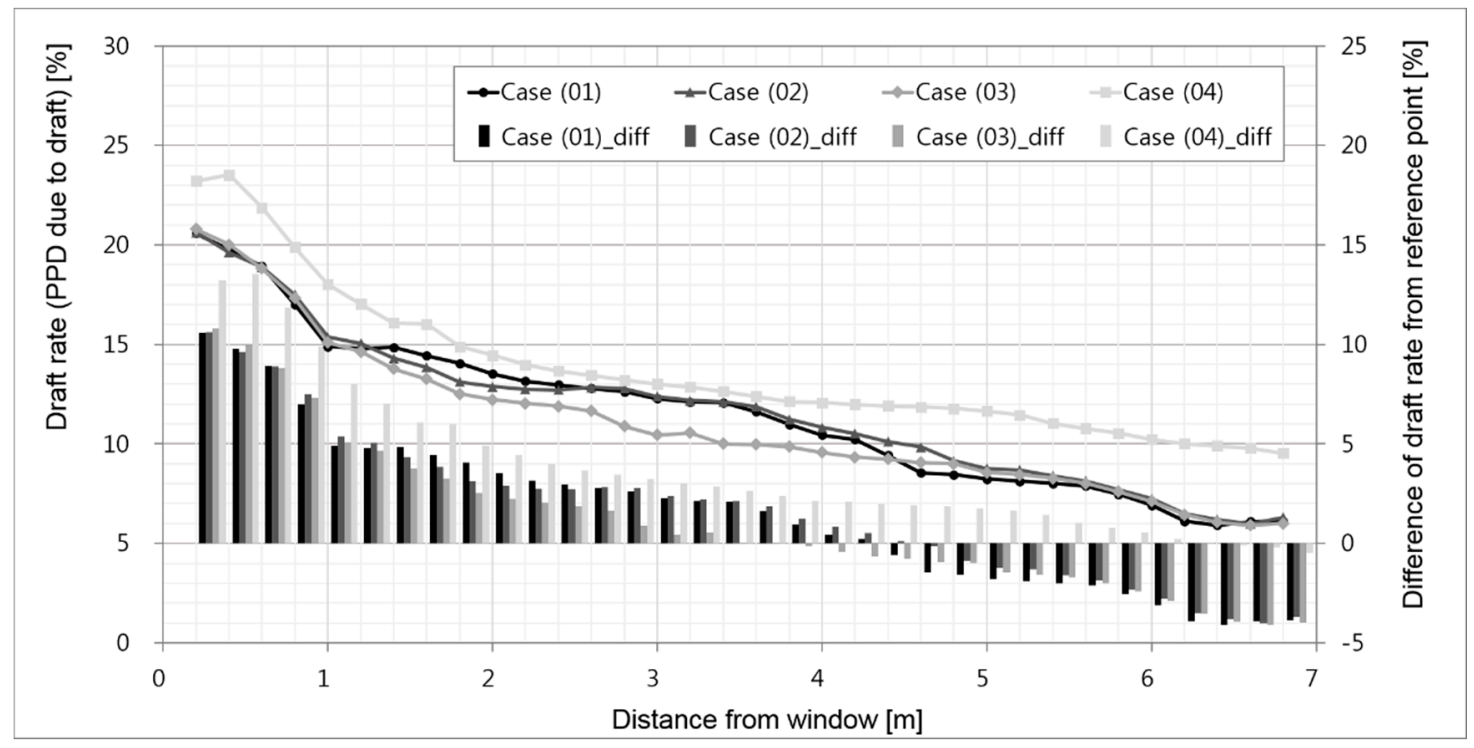

Figure 10. Draft rate by distance from window (window $U$-value is $2.7 \mathrm{~W} / \mathrm{m}^{2} \cdot \mathrm{K}$ ).

The vertical cross-sectional distribution of the draft rate according to the application of the RFHS showed that all cases met the Class B standard range, as shown in Figure 11. In cases (02) and (03), the value of the draft rate was high in the occupied zone. This is because the airflow velocity was not established at a relatively high value because the mixed flow velocity of natural convection was reduced and the attraction phenomenon of the airflow was weakened by using an appropriate heat radiation area and surface temperature. In addition, the temperature of the cold airflow was sufficiently increased compared to that in case (04), where the RFHS was applied to the entire floor. The attraction phenomenon from the window side caused by the ascending airflow of the RFHS occurred in case (01), where the radiation area of the RFHS was applied in the narrowest way.

As described earlier, the attraction phenomenon appeared as a manifestation of the Coanda effect by increasing the airflow velocity and ascending to the ceiling owing to the temperature difference between the low temperature of the window side and the high temperature of the floor surface. Thus, as the radiation area of the RFHS was applied more and more widely and the surface temperature was low, the velocity of the airflow from the floor surface decreased and the attraction phenomenon of the ascending airflow toward the window was reduced. 


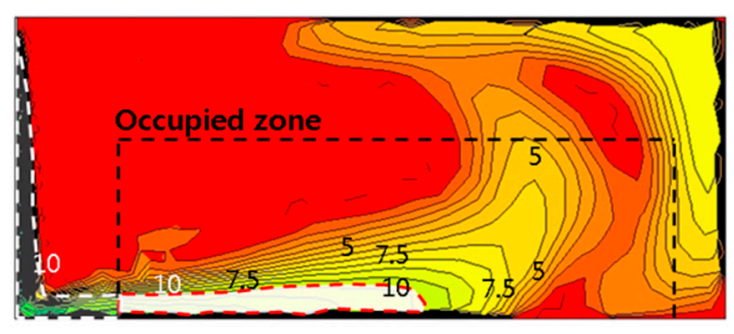

Case (1)

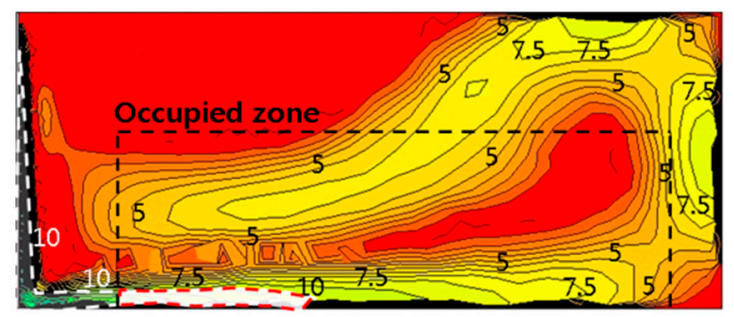

Case (3)

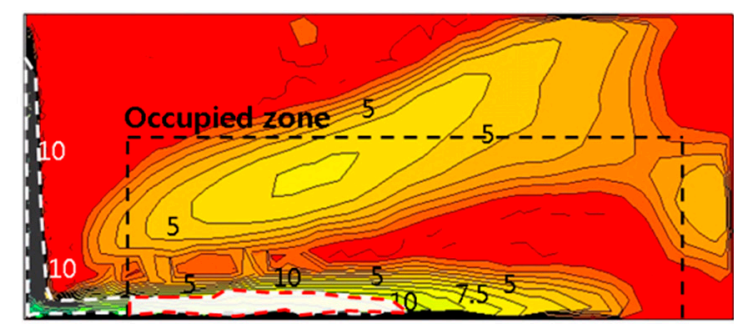

Case (2)

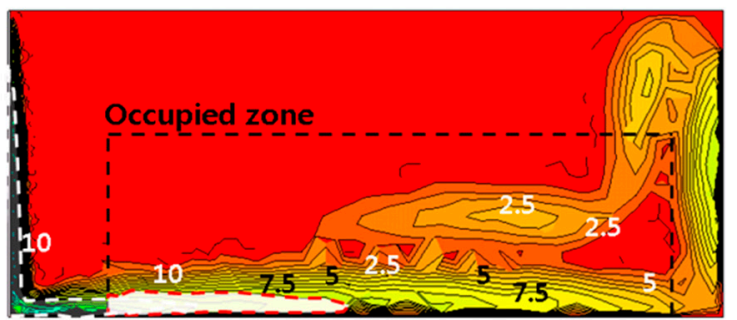

Case (4)

\section{Draft rate $[\%]$}

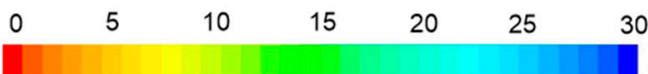

Figure 11. Draft rate distribution.

\subsection{Effect of U-Value and Window Area}

A simulation that controlled the thermal performance of the window was conducted for downdraft assessment according to the cold air around the window and the heat supplied by the RFHS.

\subsubsection{Velocity Profiles}

The space where conditions of a low-E, dual-pane glass were applied showed a relatively higher window surface temperature than the case where conditions of a general, dual-pane glass were applied, as shown in Figure 12. Accordingly, the thermal output of the RFHS applied to the room was smaller so that the surface temperature of the RFHS was reduced. Therefore, the temperature difference between airflows was reduced and the possibility of a downdraft occurring in the occupied area was also reduced as the temperature difference and the airflow velocity into the occupied area along the floor surface were reduced.

The simulation results showed that the maximum airflow velocity on the floor near the window was the highest in case (5), where the radiant heat area was the smallest, but the airflow velocity on the indoor floor was reduced. In cases (6), (7), and (8), where the surface temperature was applied to be much lower, the airflow velocity gradually decreased. From a tridimensional point of view, no airflow occurs into the ceiling through the side walls. Therefore, if the thermal performance of the window is improved, reducing the phenomenon that the airflow rises to the ceiling side deepening the downdraft can be reduced. As a result, the downdraft does not occur even if the RFHS is applied to the perimeter zone.

\subsubsection{Temperature Distribution}

In case (05), a constant air temperature distribution near the floor was shown because the influx of cold air was blocked near the window, as shown in Figure 13. In case (05), cold air entered deep into the inside of the room, but it was determined that the indoor temperature distribution did not result in occupant discomfort because it generally had a distribution similar to the indoor set temperature, and the vertical temperature difference was a maximum of $2{ }^{\circ} \mathrm{C}$. Because of improved 
window performance, floor surface temperature of RFHS is low and it means that it satisfied the comfort range of floor surface temperature.

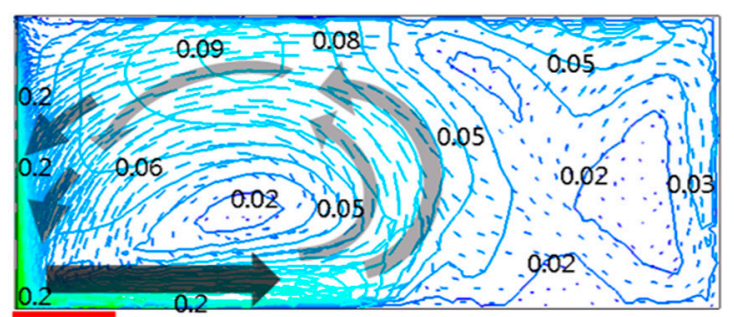

Case (5)

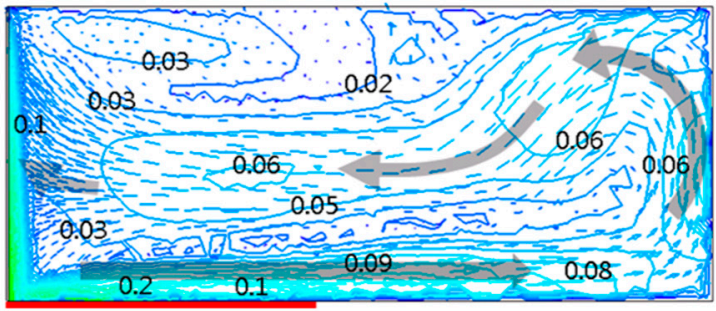

Case (7)

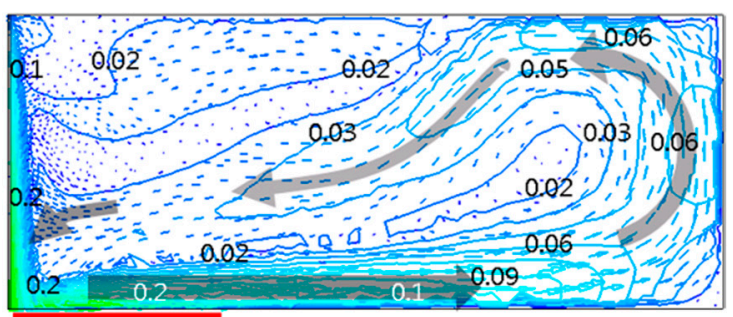

Case (6)

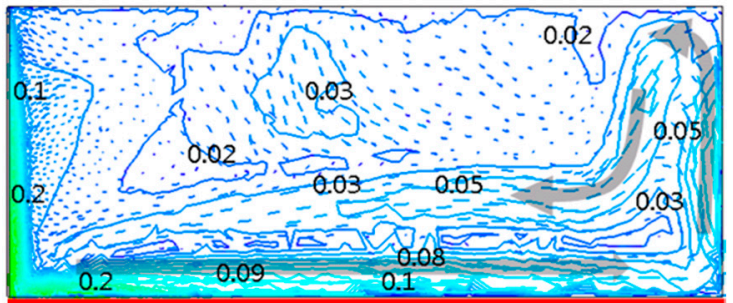

Case (8)

Velocity $[\mathrm{m} / \mathrm{s}]$

$\begin{array}{llllll}0 & 0.05 & 0.10 & 0.15 & 0.20 & 0.25\end{array}$

Figure 12. Velocity profiles.

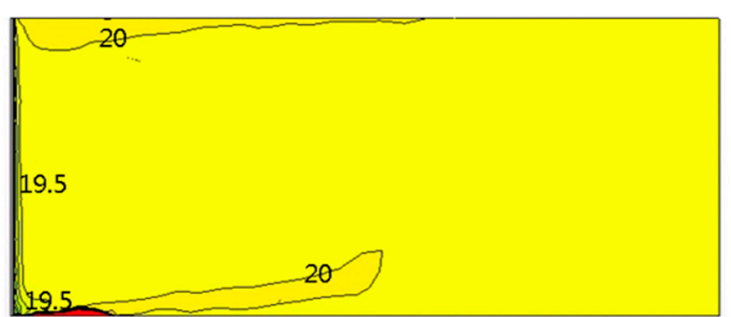

Case (5)

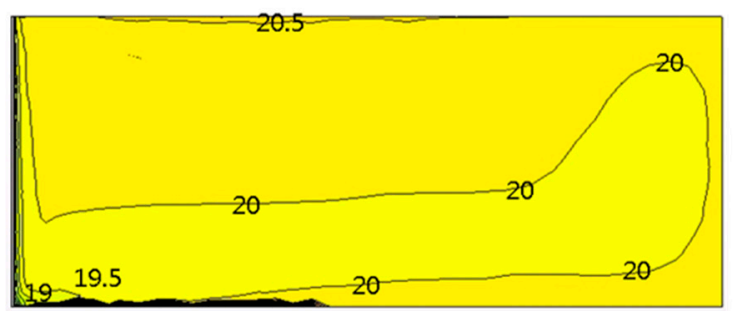

Case (7)

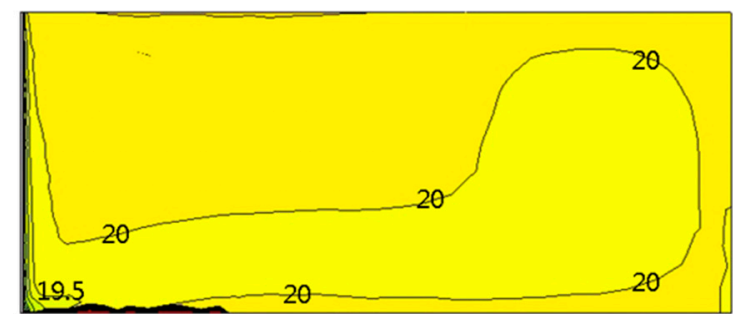

Case (6)

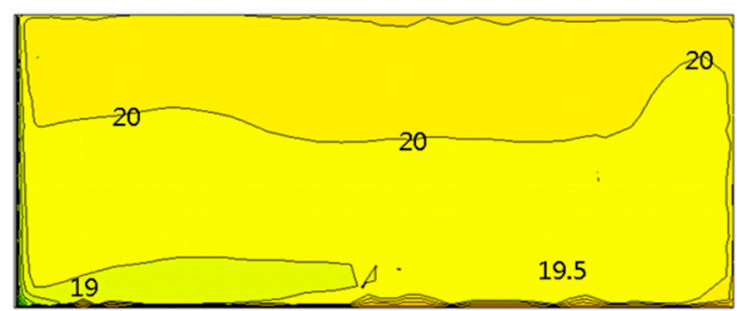

Case (8)

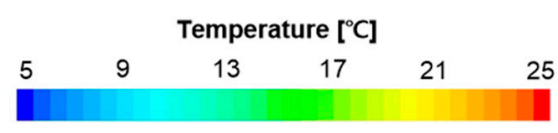

Figure 13. Distribution of temperature.

\subsubsection{Predicted Percentage of People Dissatisfied Due to Downdraft}

The draft rate distribution in the room is shown in Figure 14. All cases appeared to achieve a level that satisfied the Class B draft rate requirements. However, case (05) showed the highest temperature 
of air in the vicinity of the floor surface and a high airflow velocity, causing a higher draft rate than in other cases.

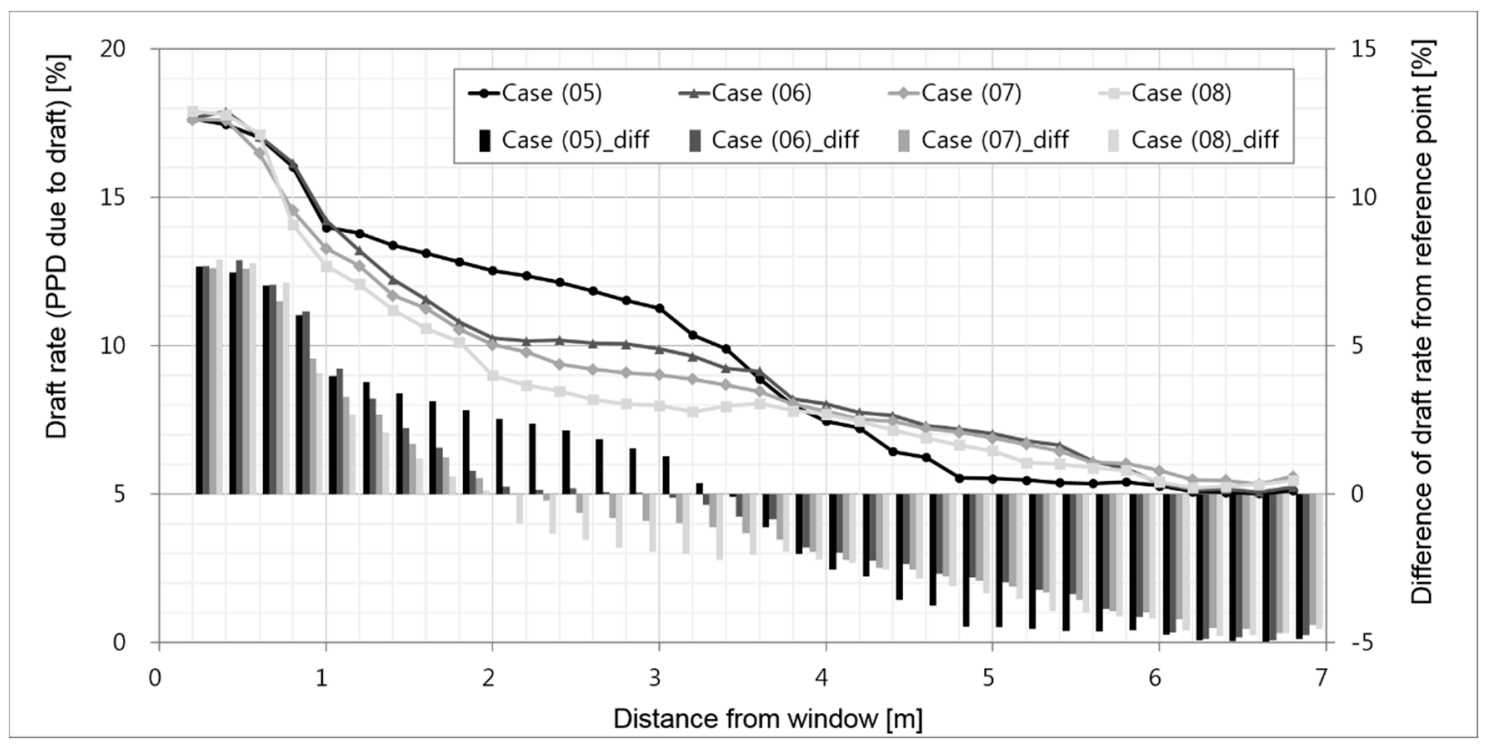

Figure 14. Draft rate by distance from window (window $U$-value is $1.75 \mathrm{~W} / \mathrm{m}^{2} \cdot \mathrm{K}$ ).

The draft rate distribution in a vertical cross section of the room is shown in Figure 15, and because a high level of window thermal performance was used, application of the RFHS showed a satisfying result in that the numerical value of the draft rate met the standard value. However, the region in which a high draft rate existed in the occupied area tended to become gradually larger as the application area of the RFHS was widened.

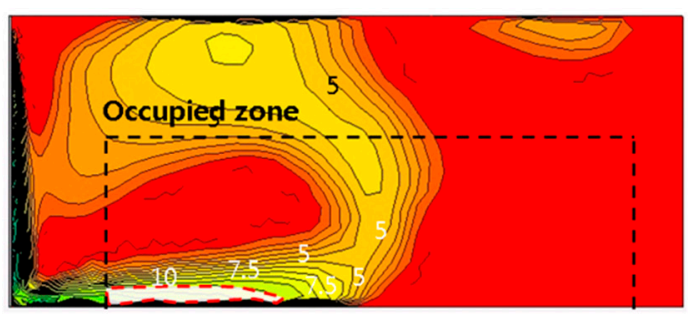

Case (5)

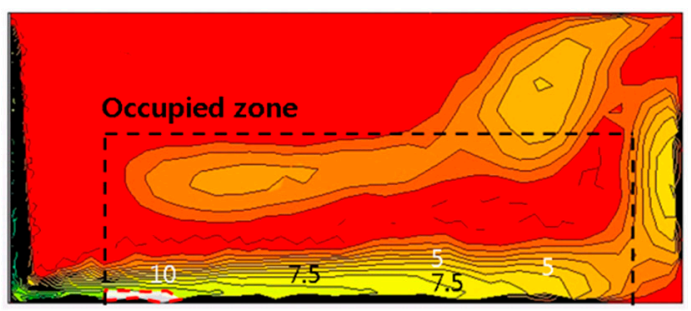

Case (7)

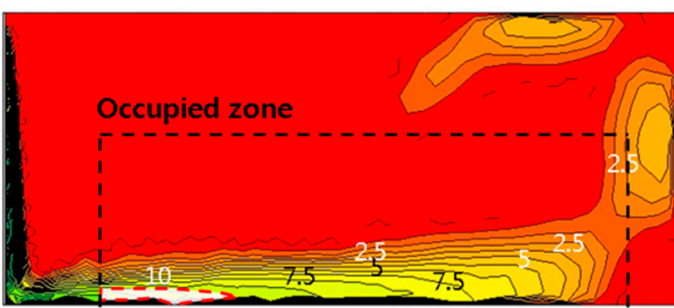

Case (6)

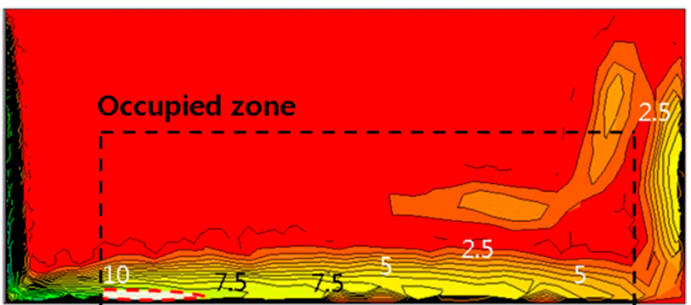

Case (8)

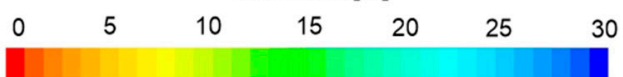

Figure 15. Draft rate distribution. 


\subsection{Effect of Window Height}

A simulation varying the height of the window was performed for downdraft assessment. The analysis showed that the draft rate exceeded the Class B level, as shown in Figure 16 (here, the reference point is DR 20\%), when the window had a high vertical height, but the result did meet the Class C level. In particular, as the radiation area of the RFHS was narrowed, the draft rate increased in the region near the window, but showed a tendency to decrease as air flowed into the occupied area. This was because the radiation area of the RFHS was wider, reducing the strength of attraction of the airflow toward the window and decreasing the airflow velocity as the radiation surface widened. If the heat insulation performance of the window were improved when the vertical height of the window was high, the draft rate appeared to be in the vicinity of the Class B level limit. Although the heat insulation performance of the window was improved, the draft rate was not significantly reduced. As mentioned previously, this was because the downdraft phenomenon is affected not by the temperature of the cold air near the window, but by the descending airflow velocity along the windows with higher vertical heights.

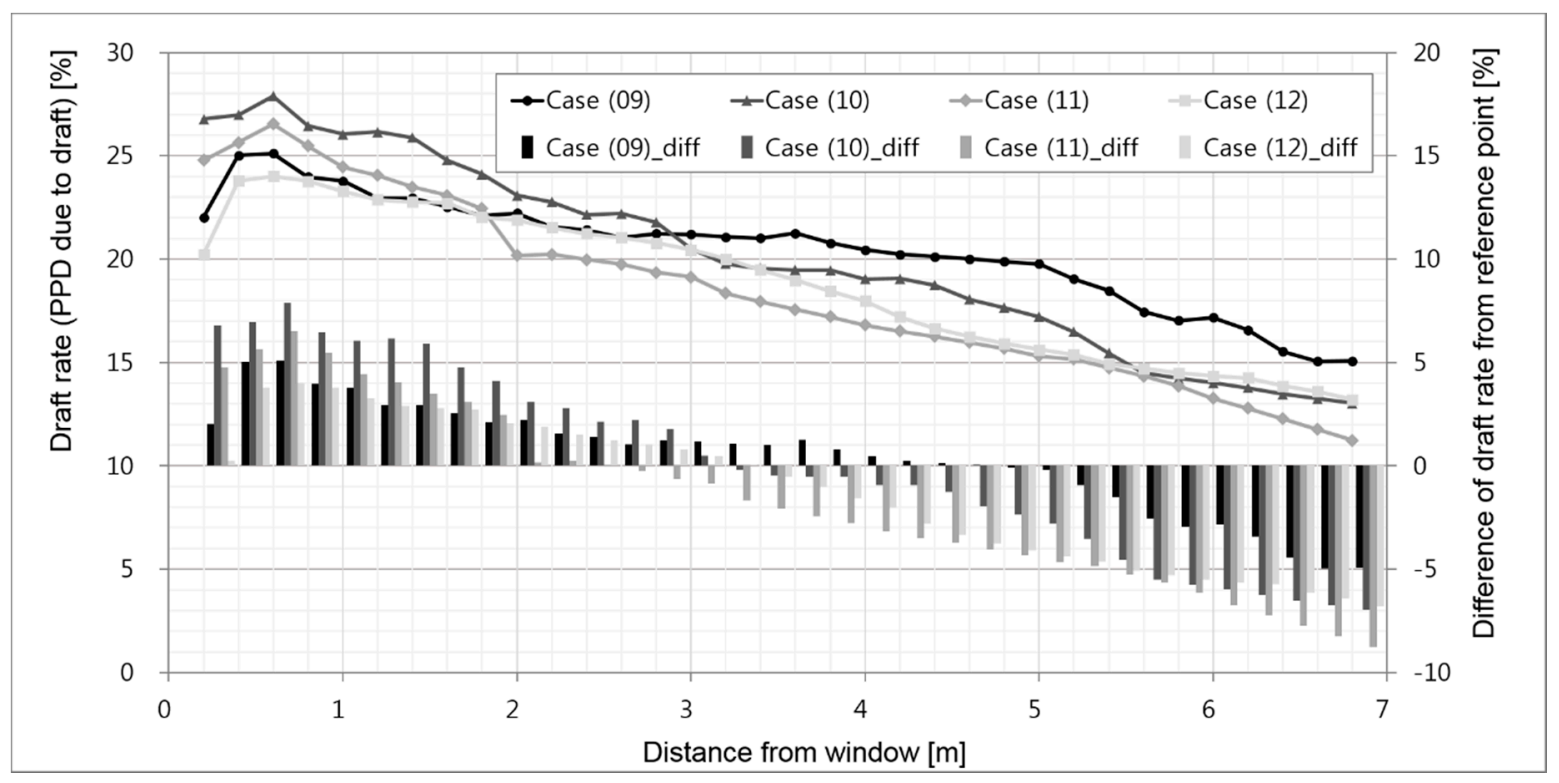

Figure 16. Draft rate by distance from window (window height is $6 \mathrm{~m}$ ).

Therefore, to reduce the downdraft where the vertical height of the window is large, the temperature difference between the heat radiating from the RFHS and the air near the window should be reduced, and the attraction of the airflow toward the window should be reduced to control the descending flow of cold air. Considering the tendency for a uniform temperature distribution to appear across the entire room, it was determined that downdraft is governed by the airflow velocity when the vertical window height is large.

\subsection{RFHS Application for Preventing Downdraft}

The relationship between an RFHS and discomfort was derived by analyzing the point at which the draft rate fell below a standard level (Class A) and the point at which the occupation area began based on CFD simulation results, taking the RFHS application method and the thermal performance of the window into account. These results are shown in Figures 17 and 18. 


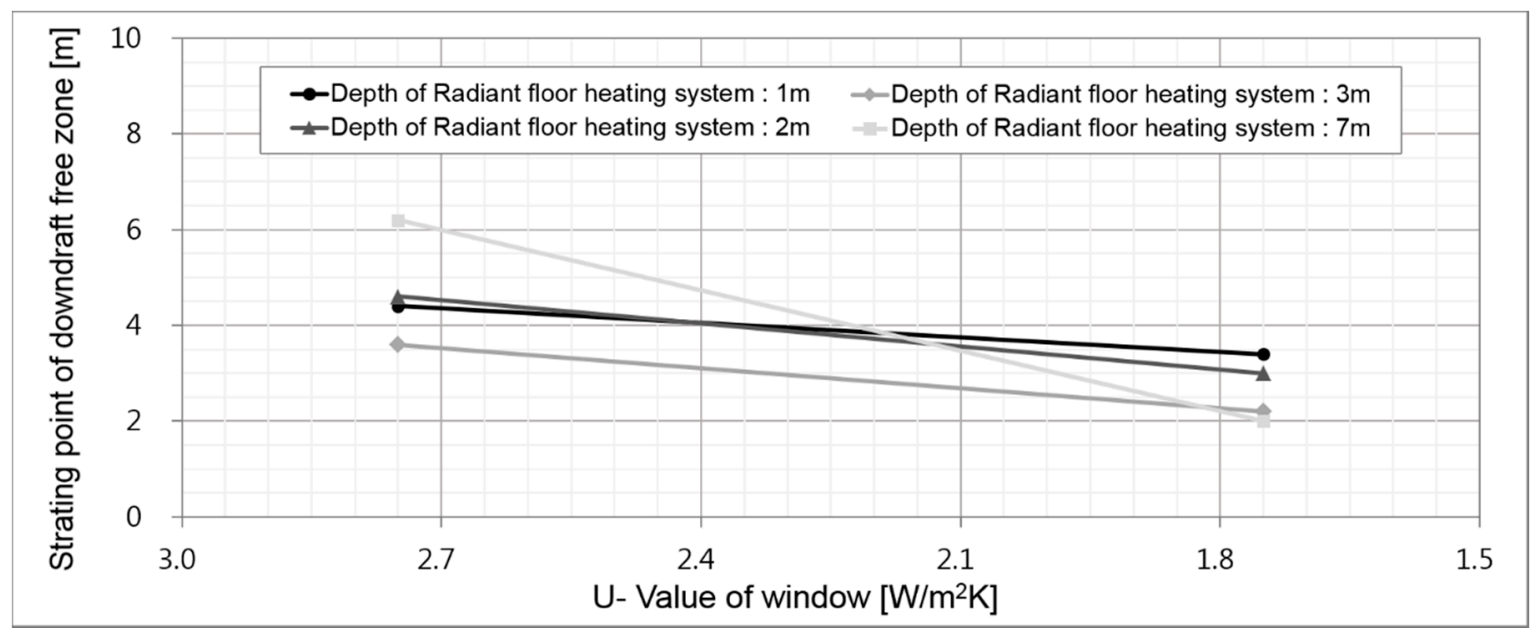

Figure 17. The relationship between RFHS and discomfort (the point when the draft rate falls below class A).

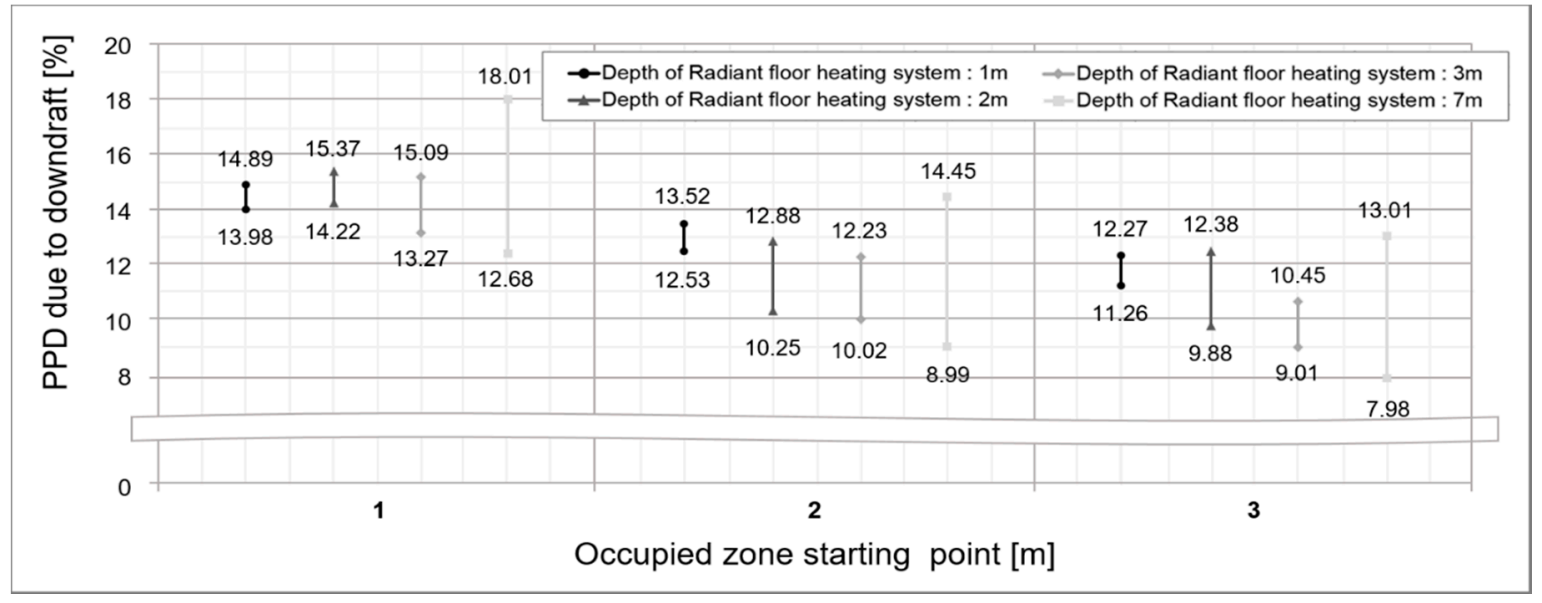

Figure 18. The relationship between RFHS and discomfort (the point when the occupation area is starting).

In a window equipped with a general level of thermal performance (general, double-paned glass), partially applying an RFHS is advantageous to prevent any downdraft occurrences. However, if the thermal performance of a window is improved to the level of low-E, dual-pane glass, increasing the area of RFHS application is more effective in preventing downdrafts. This is because if RFHS is partially applied, the descending airflow is amplified due to the Coanda effect, causing an ascending airflow along the ceiling surface.

That is, for general thermal window performance, this descending airflow was not blocked, but if the thermal performance of the window is improved, the Coanda effect is reduced and the inflow of the descending airflow into the occupant area is, at the same time, blocked. Due to recent increases in the area occupied by windows in building envelopes, downdrafts can be prevented by the principle of natural convection, even if the RFHS is applied, through the effect of heat exchange with the cold airflow. This assessment was made based on the fact that the simulation results reflected a trend of improving window thermal performance. 


\section{Conclusions}

This study performed a downdraft assessment on glass curtain wall buildings with respect to the radiation condition of the RFHS and the thermal performance of the window. The results obtained are as follows.

For the downdraft assessment, the RFHS applied to perimeter zones with different window types was modeled using CFD simulation. The simulation result showed that most values, such as airflow velocity, temperature, and draft rate, satisfied the downdraft assessment criteria because of the ascending airflow caused by the radiant heat from the floor during the RFHS application and the radiant heat transfer effect between the RFHS and the window.

In addition, the temperature rise of cold air through heat radiation along the floor and the related cold airflow reduction phenomena in the descending air flow were derived based on the mechanism of preventing the downdraft with the RFHS application. The temperature difference between the air supplied through the RFHS and the air descending along the cold surface of the window increased when the RFHS was applied to a narrow area with a high temperature. The airflow velocity also increased with the heat exchange. The airflow re-entered the window side, and the downdraft in the occupied area exceeded the strict value specified by the standards. Conversely, if heat were applied according to the indoor thermal output by widening the radiant heat area of the RFHS, a downdraft could occur as a result of a blocking failure prior to the influx of the cold air into the occupied area caused by low surface temperatures. Therefore, applying the RFHS is advantageous in a perimeter zone without causing airflow inducement at the window side with acceptable surface temperatures.

If the vertical height of the window were larger, the downdraft phenomenon was more influenced not by the cold air from the window, but by the velocity of the airflow descending along the window. Thus, the velocity of the cold airflow must be reduced as the vertical height of the window increases. To this end, the temperature difference between the air from the window and the radiating air from the RFHS should be reduced. Moreover, the cold air influx phenomenon at the window should be minimized by heated air ascending toward the window by designing a wider radiation area.

Acknowledgments: This research was supported by Basic Science Research Program through the National Research Foundation of Korea (NRF) funded by the Ministry of Education (NRF-2015R1D1A1A09061467).

Author Contributions: Goosang Joe and Dongwoo Kim conceived and designed the simulation; Goosang Joe and Sojeong Park performed the simulation; Goosang Joe, Sanghoon Park and Myoungsouk Yeo analyzed the data; Goosang Joe wrote the paper; Myoungsouk Yeo and Kwangwoo Kim supervised the paper writing.

Conflicts of Interest: The authors declare no conflict of interest.

\section{References}

1. Rhee, K.N.; Kim, K.W. A 50 year review of basic and applied research in radiant heating and cooling systems for the built environment. Build. Environ. 2015, 91, 166-190. [CrossRef]

2. Salt, H. Preliminary design considerations for a rockbed/floor space-heating system. Build. Environ. 1985, 20, 221-231. [CrossRef]

3. American Society of Heating, Refrigerating, and Air Conditioning Engineers (ASHRAE). ASHRAE Handbook-HVAC Systems and Equipment; ASHRAE: Atlanta, GA, USA, 2012.

4. Heiselberg, P.; Overby, H.; Bjørn, E. Energy-Efficient Measures to Avoid Downdraft from Large Glazed Facades. ASHRAE Trans. 1995, 101, 1127-1135.

5. Feustel, H.E.; Stetiu, C. Hydronic radiant cooling-preliminary assessment. Energy Build. 1995, 22, $193-205$. [CrossRef]

6. Li, S.; Joe, J.; Hu, J.; Karava, P. System identification and model-predictive control of office buildings with integrated photovoltaic-thermal collectors, radiant floor heating and active thermal storage. Sol. Energy 2015, 113, 139-157. [CrossRef]

7. Shin, D.U. Control Strategy for the Experiment of Evaluation the Thermal Output of Radiant Floor Heating Panels. Master's Thesis, Seoul National University, Seoul, Korea, 2010. 
8. Sharda, A.; Kumar, S. Comparative study of simulation and experimentation for the $U$-value of double-glazed windows with inter-pane blinds. Sci. Technol. Built Environ. 2015, 21, 179-189. [CrossRef]

9. Gao, T.; Ihara, T.; Grynning, S.; Jelle, B.P.; Lien, A.G. Perspective of aerogel glazings in energy efficient buildings. Build. Environ. 2016, 95, 405-413. [CrossRef]

10. Park, S.H.; Chung, W.J.; Yeo, M.S.; Kim, K.W. Evaluation of the thermal performance of a Thermally Activated Building System (TABS) according to the thermal load in a residential building. Energy Build. 2014, 73, 193-205. [CrossRef]

11. Chung, W.J.; Park, S.H.; Yeo, M.S.; Kim, K.W. Control of Thermally Activated Building System Considering Zone Load Characteristics. Sustainability 2017, 9, 586. [CrossRef]

12. Fanger, P.O. Air turbulence and sensation of draught. Energy Build. 1988, 12, 21-39. [CrossRef]

13. Atlanta, American Society of Heating, Refrigerating, and Air-Conditioning Engineers (ANSI/ASHRAE). ANSI/ASHRAE Standard: Thermal Environmental Conditions for Human Occupancy; ANSI/ASHRAE: Atlanta, GA, USA, 2013; p. 55.

14. International Organization for Standardisation (ISO). ISO 7730: Ergonomics of the Thermal Environment-Analytical Determination and Interpretation of Thermal Comfort Using Calculation of the PMV and PPD Indices and Local Thermal Comfort Criteria; ISO: Geneva, Switzerland, 2013.

15. Heiselberg, P. Draught risk from cold vertical surfaces. Build. Environ. 1994, 29, 297-301. [CrossRef]

16. Lyons, P.; Arasteh, D.; Huizenga, C. Window Performance for Human Thermal Comfort. ASHRAE Trans. 2000, 106, 594-602.

17. Larsson, U.; Moshfegh, B. Experimental investigation of downdraught from well-insulated windows. Build. Environ. 2002, 37, 1073-1082. [CrossRef]

18. Zukowski, M. A new formula for determining a minimum recommended value of inlet air velocity from UFAD system to prevent occupants from draught risk. Build. Environ. 2007, 42, 171-179. [CrossRef]

19. Olesen, B.W. Vereinfachte methode zur vorausberechnung des thermischen raumklimas. Heiz. Luftung Klima Haustech. 1995, 46, 219-225.

20. Manz, H.; Frank, T. Analysis of thermal comfort near cold vertical surfaces by means of computational fluid dynamics. Indoor Built Environ. 2004, 13, 233-242. [CrossRef]

21. Ge, H.; Fazio, P. Experimental investigation of cold draft induced by two different types of glazing panels in metal curtain walls. Build. Environ. 2004, 39, 115-125. [CrossRef]

22. Schellen, L.; Timmers, S.; Loomans, M.G.L.C.; Nelissen, E.S.M.; Hensen, J.L.M.; van Marken Lichtenbelt, W.D. Downdraught assessment during design: Experimental and numerical evaluation of a rule of thumb. Build. Environ. 2012, 57, 290-301. [CrossRef]

23. Jurelionis, A.; Isevičius, E. CFD predictions of indoor air movement induced by cold window surfaces. J. Civ. Eng. Manag. 2008, 14, 29-38. [CrossRef]

24. Myhren, J.A.; Holmberg, S. Flow patterns and thermal comfort in a room with panel, floor and wall heating. Energy Build. 2008, 40, 524-536. [CrossRef]

25. Mustakallio, P.; Kosonen, R.; Korinkova, A. Full-scale test and CFD-simulation of radiant panel integrated with exposed chilled beam in heating mode. Build. Simul. 2017, 10, 75-85. [CrossRef]

26. Shia-hui, P.; Peterson, F. Convection from a cold window with simulated floor heating by means of transiently heated flat unit. Energy Build. 1995, 23, 95-103. [CrossRef]

27. Kulkarni, R. Natural Convection in Enclosures with Localised Heating and Cooling. Ph.D. Thesis, Department of Mechanical Engineering, University of Wollongong, Wollongong, Australia, 1998.

28. Eckert, E.R.G.; Jackson, T.W. Analysis of Turbulent Free-Convection Boundary Layer on Flat Plate; National Advisory Committee for Aeronautics: Cleveland, OH, USA, 1951; pp. 255-261.

29. Star-CCM+. Tutorial Guide; Siemens Inc.: München, Germany, 2017.

30. International Organization for Standard (ISO). ISO 11855-2:2012(E) Building Environment Design e Design, Dimensioning, Installation and Control of Embedded Radiant Heating and Cooling Systems. Part 2: Determination of the Design Heating and Cooling Capacity; ISO: Geneve, Switzerland, 2012.

31. CEN; BS EN 1264-2. Water Based Surface Embedded Heating and Cooling Systems. Floor Heating: Prove Methods for the Determination of the Thermal Output Using Calculation and Test Methods; EU: Brussels, Belgium, 2009. 
32. Wang, Z.; Zhang, H.; Arens, E.; Lehrer, D.; Huizenga, C.; Yu, T.; Hoffmann, S. Modeling thermal comfort with radiant floors and ceilings. In Proceedings of the 4th International Building Physics Conference, Istanbul, Turkey, 15-18 June 2009.

33. European Committee for Electrotechnical Standardization (CENELEC). Temperatures of Hot Surfaces Likely to Be Touched; CENELEC Guide 29; CENELEC: Brussels, Belgium, 2007. 